\title{
Influence of divalent cations in the protein crystallization process assisted by Lanthanide-based additives.
}

\author{
Amandine Roux, ${ }^{\dagger+}$ Romain Talon,,$^{\dagger}$ Zaynab Alsalman, ${ }^{\dagger}$ Sylvain Engilberge, ${ }^{\dagger}$ Anthony D’Aléo, ${ }^{\dagger}$ \\ Sebastiano Di Pietro, ${ }^{\dagger}$ Adeline Robin, ${ }^{\dagger}$ Alessio Bartocci, ${ }^{\dagger}$ Guillaume Pilet, ${ }^{\ddagger}$ Elise Dumont, ${ }^{\dagger},{ }^{\dagger}$ Tristan \\ Wagner, ${ }^{\complement,}$ Seigo Shima, ${ }^{\complement}$ François Riobé ${ }^{\dagger *}$ Eric Girard, ${ }^{\dagger *}$ Olivier Maury ${ }^{\dagger *}$
}

† Univ Lyon, ENS de Lyon, CNRS UMR 5182, Laboratoire de Chimie, F-69342 Lyon, France. E-mail: olivier.maury@enslyon.fr, francois.riobe@ens-lyon.fr,

₹ Polyvalan, F-69342 Lyon, France.

† Univ Grenoble Alpes, CEA, CNRS, IBS, F-38000 Grenoble, France. E-mail: eric.girard@ibs.fr.

f Univ de Lyon, CNRS UMR 5615, Université Claude Bernard Lyon 1, 43 boulevard du 11 novembre 1918, F-69622

Villeurbanne cedex, France.

+ Institut Universitaire de France, 1 rue Descartes, 75005 Paris, France.

${ }^{\varsigma}$ Microbial Protein Structure Group, Max Planck Institute for Terrestrial Microbiology, Karl-von-Frisch-Str. 10, D-35043

Marburg, Germany.

$¥$ Microbial Metabolism Group, Max Planck Institute for Marine Microbiology, 1-Celsiusstrasse, 35043 Bremen, Germany.

\section{Supporting Information Placeholder}

\begin{abstract}
The use of lanthanide complexes as powerful auxiliaries for biocrystallography prompted us to systematically analyze the influence of the commercial crystallization kit composition on the efficiency of two lanthanide additives: [Eu(DPA) $\left.]_{3}\right]^{3-}$ and TbXo4. This study reveals that the tris-dipicolinate complex presents a lower chemical stability and a strong tendency to false positives which are detrimental for its use in high-throughput robotized crystallization platform. In particular, crystal structures of $\left(\mathrm{Mg}\left(\mathrm{H}_{2} \mathrm{O}\right)_{6}\right)_{3}\left[\mathrm{Eu}(\mathrm{DPA})_{3}\right]_{2} \cdot 7 \mathrm{H}_{2} \mathrm{O}(\mathbf{1}),\left\{\left(\mathrm{Ca}\left(\mathrm{H}_{2} \mathrm{O}\right)_{4}\right)_{3}\left[\mathrm{Eu}(\mathrm{DPA})_{3}\right]_{2}\right\}_{\mathrm{n}} \cdot 11 \mathrm{nH}_{2} \mathrm{O}(\mathbf{2})$ and $\left\{\mathrm{Cu}(\mathrm{DPA})\left(\mathrm{H}_{2} \mathrm{O}\right)_{2}\right\}_{\mathrm{n}}(3)$ resulting from spontaneous crystallization in the presence of divalent alkaline earth cation and transmetallation are reported. On the other hand, the Tb-Xo4 is perfectly soluble in the crystallization media, stable in the presence of alkaline-earth dications and slowly decomposed (within days) by trans-metalation with transition metals. The original structure of $\left[\mathrm{Tb}_{4} \mathrm{~L}_{4}\left(\mathrm{H}_{2} \mathrm{O}\right)_{4}\right] \mathrm{Cl}_{4} \cdot 15 \mathrm{H}_{2} \mathrm{O}(4)$ is also described. This article also highlight a potential synergy of interactions between the $\mathrm{Tb}-\mathrm{Xo} 4$ and components of the crystallization mixtures leading to the formation of complex adducts like $\left\{\right.$ AdkA/Tb-Xo4/ $/ \mathrm{Mg}^{2+} /$ glycerol $\}$ in the protein binding sites. The observation of such multicomponents adducts illustrated the complexity and versatility of the supramolecular chemistry occurring at the surface of proteins.
\end{abstract}

\section{Introduction}

During this last decade, the number of protein structures deposited in the Protein Data Bank (PDB https://www.rcsb.org/) has increased steadily despite the emergence of alternative techniques, like NMR or cryoEM and almost $90 \%$ of new deposited structures are elucidated using X-ray crystallography. However, this last method still suffers two major chokepoints that severely reduced the efficiency of its implementation: i) the production of high-quality single crystals and ii) the phase determination mandatory for electron density map calculation. ${ }^{1-3}$ Currently, the structural genomics statistics estimated that only $10 \%$ of the purified proteins will see their structure solved and consequently a considerable room for improvement. ${ }^{2}$ To tackle these drawbacks, most of developments are concentrated in the field of technology with the improvement of structure determination pipelines, more intense radiation sources or the use of XFEL source to address even smaller crystals, and the routine use of high-throughput crystallization platforms to screen an even larger number of conditions with a reduced amount of sample..$^{4-5}$ Unfortunately, the certain success of these developments led, in comparison, to neglect the traditional methodological approaches. In particular, the research for new additives that can solved either the crystallization or the phase determination problems or better both simultaneously is a real promising way for improvement in the field for a moderate cost.

Indeed, it is well known that incorporation in a protein crystal of well-ordered heavy atom enable to solve the phase problem using anomalous-based methods - Single-wavelength Anomalous Dispersion (SAD) and Multi-wavelengths Anomalous Dispersion (MAD). ${ }^{6}$ These heavy atoms can be implemented in a covalent way pioneered by the Doublié's Sto-Se replacement using selenomethionine or in a non-covalent one using transition metal salts $(\mathrm{Hg}, \mathrm{Pt} . .$.$) or lanthanide$ 
complexes. ${ }^{7}$ On the other hand, the development of additives to facilitate the nucleation process was initially focused on heterogeneous compounds like minerals, natural materials such as horse and human hair, nano-porous materials ${ }^{8-9}$ and more recently molecular imprinted polymers. ${ }^{10-11}$ However, these solid additives are hardly compatible with the generalized homogeneous high-throughput crystallization methods used nowadays. i)

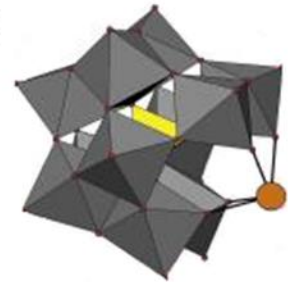

iii)

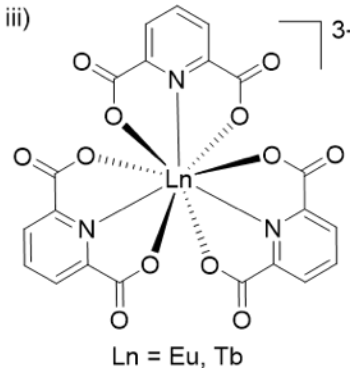

ii)

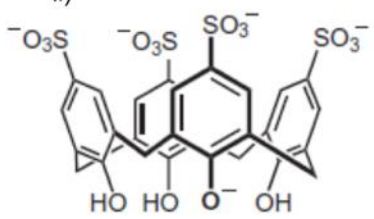

iv)

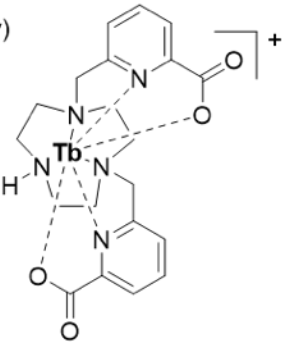

Figure 1. Selected examples of the three families of soluble additives used in protein crystallography. (i) Keggin polyoxometalate structure of $\left[\mathrm{Ce}\left(\alpha-\mathrm{PW}_{11} \mathrm{O}_{39}\right)_{2}\right]^{10-}$, (ii) $\mathrm{p}$ sulfonatocalix [4]arene (slx4) and lanthanide derivatives studied in this work (iii) tris-dipicolinate $\left[\operatorname{Ln}(\mathrm{DPA})_{3}\right]^{3-}$ and (iv) crystallophore (Tb-Xo4).

Recently, new soluble additives were developed that are fully compatible with the above-mentioned robotized crystallization screening systems (Figure 1): i) the polyoxo-metalates developed by Rompel and co-workers, ${ }^{12-15}$ ii) the anionic macrocycles proposed by the team of Crowley (phosphonated or sulfonato-calix[4,6]arenes, cucurbituryl...), ${ }^{16-19}$ and the lanthanide complexes (iii) tris-dipicolinate ${ }^{20-21}$ and iv) crystallophore (Tb-Xo4), ${ }^{22}$ reported by our group. All these species can be considered as "molecular glues" inducing a network of supramolecular interactions with proteins in solution and favoring crystalline contacts in the crystal packing. Among these three families of additives, polyoxometalate and lanthanide complexes contain heavy atoms (tungsten, europium or terbium, respectively) and can therefore solve simultaneously the nucleating and the phase determination issues. In particular, based on our own statistics obtained on twenty soluble proteins, the crystallophore increases the number of crystallization conditions by a factor $3-$ to- $7,,^{22}$ gives better quality crystals generally suppressing twinning issue and enables de novo phasing in more than $80 \%$ of the cases even in complicated ones where selenation was unsuccessful. ${ }^{23}$ Furthermore, Tb-Xo4 was also shown to be compatible with micro-seeding, counter-diffusion crystallization methods and serial crystallography (mesh-and-collect method). ${ }^{23-24}$ Both $[\mathrm{Na}]_{3}\left[\mathrm{Eu}(\mathrm{DPA})_{3}\right]$ and $\mathrm{Tb}-\mathrm{Xo} 4$ complexes are now available and frequently exploited by the biocrystallographers community to solve the structure of protein of biological interest either for nucleation and/or for phasing steps. ${ }^{25-31}$ As a consequence, they have been involved in crystallization processes according to the state-of-the-art high-throughput protocols using pipetting robots, and conventional commercial kits. During the course of these studies, several unexpected results have been obtained suggesting the interaction of the lanthanide complexes with the crystallization condition mixtures that can lead to false positive crystallization results or apparent cooperative behavior favoring the lanthanide complex/protein interaction.

In this article, we described two representative examples of such unexpected results: a false positive observed during the crystallization of the Acriflavine resistant protein B from Escherichia coli in the presence of $\left[\mathrm{Na}_{3}\left[\mathrm{Eu}(\mathrm{DPA})_{3}\right]\right.$ and an apparent cooperative behavior in the crystal structure of adenylate kinase protein from Methanothermococcus thermolithotrophicus in the presence of $\mathrm{Tb}-\mathrm{Xo} 4$. In order to rationalize these results, we explored the behavior of our Lnbased additives in the conventional crystallization kits with a particular focus on the role of divalent alkaline earth or transition metal dications and evidenced detrimental autocrystallization processes and trans-metalation reactions.

\section{Results and discussions}

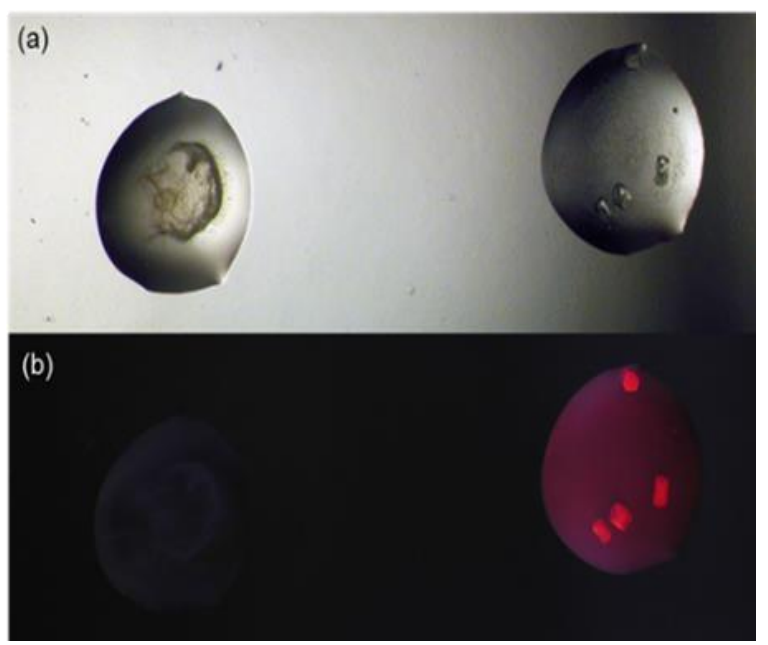

Figure 2. Crystallization drops of Ec-AcrB alone (left) and in the presence of $\left[\mathrm{Eu}(\mathrm{DPA})_{3}\right]^{3-}$ (right) in transmission (a) or under $315 \mathrm{~nm}$ irradiation (b).

The crystallization of Acriflavine resistant protein B from Escherichia coli (Ec-AcrB), a homotrimeric membrane protein (341 kDa) whose structure was already described (PDB id code: $2 \mathrm{GIF}$ ), was performed in the presence and in absence of $[\mathrm{Na}]_{3}\left[\mathrm{Eu}(\mathrm{DPA})_{3}\right]$ using the High-throughput Crystallization facility (HTXlab, EMBL-Grenoble) with six commercial crystallization kit (see experimental). The drops were regularly imaged to detect the crystallization events and study the effect of the lanthanide additive. A typical comparison is reported in the Figure 2; the protein alone precipitates as an amorphous slurry whereas in the presence of $\left[\mathrm{Eu}(\mathrm{DPA})_{3}\right]^{3-}$ exploitable crystals have been obtained that were strongly luminescent under UV-irradiation (Figure 2). However, after analysis, these crystals did not contain any protein and are simply composed of pure $\left[\mathrm{Eu}(\mathrm{DPA})_{3}\right]^{3-}$. Consequently, the self-crystallization of 
such lanthanide complex is a typical example of false positive hampering practical co-crystallization experiments with proteins.

The second unexpected result was obtained during another project where a systematic use of crystallophore on proteins fractions obtained from the marine organism Methanothermococcus thermolithotrophicus allows us to solve four unknown protein structures, ${ }^{23,30-31}$ including the adenylate kinase protein (AdkA). The structure of AdkA (PDB id code: 6HF7) was solved at $1.96 \AA$ resolution in a condition containing $50 \mathrm{mM}$ of magnesium ion (see SI for details). The asymmetric unit contains the biological unit consisting in a homo-trimer (Figure 3a) and four bound Tb-Xo4 among which two, with the highest occupancy (0.7) were unambiguously modelled. These latter are located at the same location on two AdkA monomers, and thus involve an identical supramolecular interactions network. The analogous site on third protein monomer is unoccupied. A detailed investigation of the binding pocket reveals the involvement of a hydrated magnesium bridging the crystallophore to the surface protein through aspartate 90 (Figure 3b). The second feature is the presence of a glycerol (GOL) molecule contained in the protein buffer, completing the coordination sphere of the terbium ion. Starting from this crystal structure, this main binding site was investigated using DFT calculation (see ESI for details). The strongest interaction involves the hydrated magnesium and the aspartate residue (D90) ensuring the binding of the crystallophore to AdkA surface and corresponding to an interaction energy of -25.3 kcal.mol ${ }^{-1}$. This surprising formation of a $\left\{\mathrm{Tb}-\mathrm{Xo} 4 / \mathrm{Mg}^{2+}\right\}$ adduct in the interaction pocket of AdkA can be compared to the recently reported structure of the protein FprA with the observation of a $\left\{\mathrm{FprA} / \mathrm{Tb}-\mathrm{Xo} 4 / \mathrm{Ca}^{2+}\right\}$ adduct. ${ }^{32}$ In both cases, the alkaline-earth cation $\left(\mathrm{Mg}^{2+}\right.$ or $\left.\mathrm{Ca}^{2+}\right)$ was present in the crystallization mixture as well as a glycerol molecule, near TbXo4.

These unexpected and reproducible results prompted us to investigate the behavior of the two complexes $[\mathrm{Na}]_{3}\left[\mathrm{Eu}(\mathrm{DPA})_{3}\right]$ and $\mathrm{Tb}-\mathrm{Xo} 4$ with the different constituents of several commercial crystallization kits routinely used for automated crystallization experiments at the HTXlab (EMBL, Grenoble). These kits encompassed a total of 576 conditions depending on the $\mathrm{pH}$ and nature of the buffer (TRIS, MES, HEPES, citric acid, sodium acetate...), the presence of salts at different concentrations $\left(\mathrm{NaCl},\left(\mathrm{NH}_{4}\right)_{2} \mathrm{SO}_{3}, \mathrm{MgCl}_{2}, \mathrm{CaCl}_{2} \ldots\right)$ or of precipitants (such as polyethyleneglycol, methyl-2,4pentanediol, isopropanol...). In order to evaluate the behavior of our Ln-based additives in such media, the lanthanide complexes were systematically tested alone in the conventional crystallization kits. The experiment was performed by mixing equal volume of the additive solution at the desired concentration (10-100 $\mathrm{mM}$ for Tb-Xo4, 25-100 $\mathrm{mM}$ for $\left.[\mathrm{Na}]_{3}\left[\mathrm{Eu}(\mathrm{DPA})_{3}\right]\right)$ with the crystallization solution to form the sitting drop (Tables S1 and S2). Drops were then evaluated for the presence of potential self-crystallization or precipitate formation by conventional imaging techniques and for the instability of the complexes by the disappearance of the lanthanide emission signal under UV irradiation.
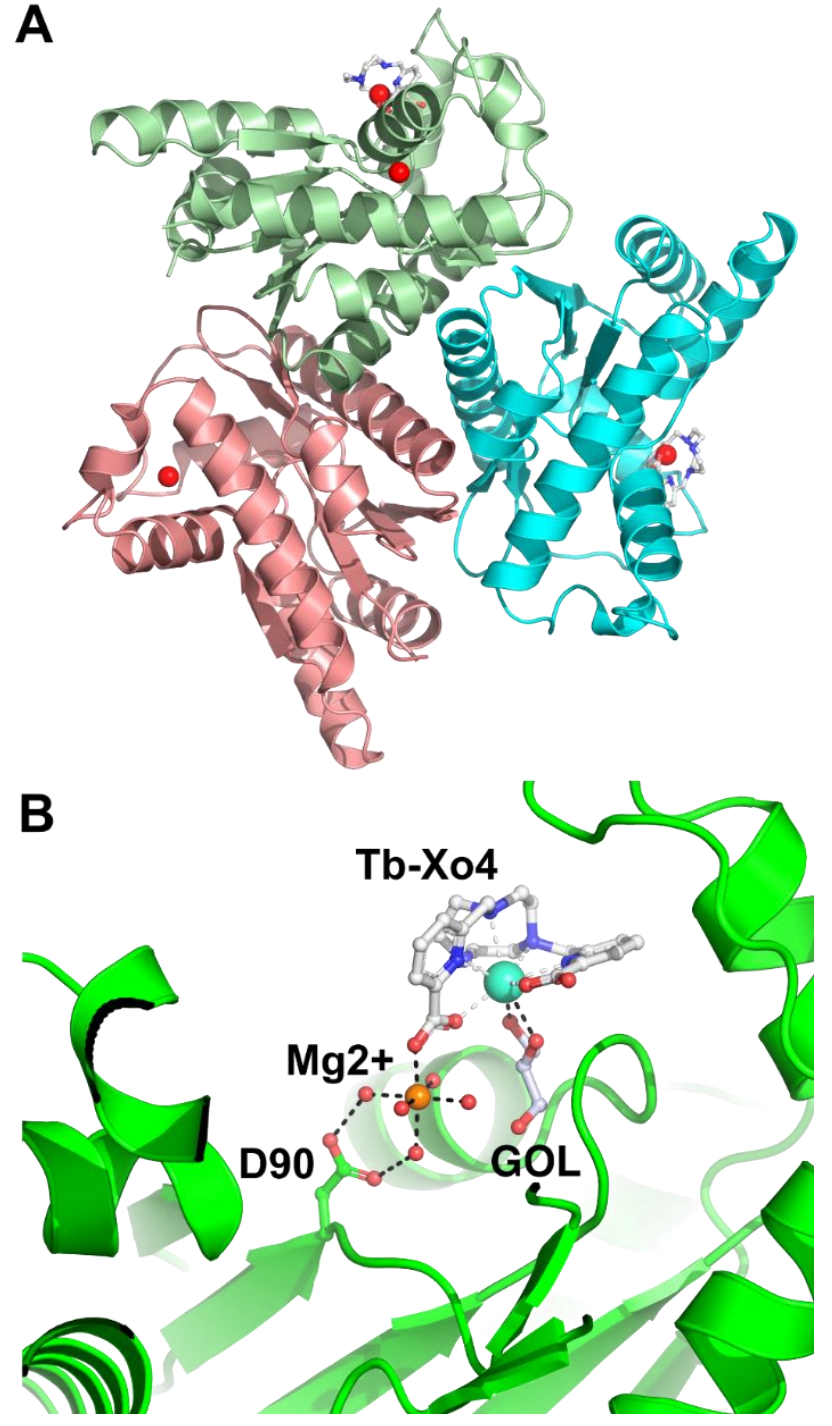

Figure 3. A) Trimer of AdkA co-crystallized with $10 \mathrm{mM} \mathrm{Tb}-$ $\mathrm{Xo} 4\left(\mathrm{~Tb}^{3+}\right.$ in blue) in the presence of $\mathrm{MgCl}_{2}\left(\mathrm{Mg}^{2+}\right.$ in grey); $\left.\mathrm{B}\right)$ Insights into the $\mathrm{Tb}-\mathrm{Xo} 4$ main binding site.

Interestingly, the spontaneous crystallization of $[\mathrm{Na}]_{3}\left[\mathrm{Eu}(\mathrm{DPA})_{3}\right]$ was observed in $10 \%$ of the conditions at 25 $\mathrm{mM}$ and this ratio increased up to $30 \%$ at $100 \mathrm{mM}$. The analysis of these conditions indicated that high concentrations of salt (such as $\mathrm{NaCl},\left(\mathrm{NH}_{4}\right)_{2} \mathrm{SO}_{3} \ldots$ ), typically higher than $0.8 \mathrm{M}$, the presence of divalent salts $\left(\mathrm{Ca}^{2+}, \mathrm{Mg}^{2+}\right)$ and 2-methyl-2,4pentanediol or isopropanol favored the self-crystallization of the tris-dipicolinate complex. If the increase of the anionic strength or the decrease of the solubility of the complex in the presence of alcohol in the media are classical ways to promote crystallization, the effect of divalent cations was less expected. Therefore, the reactions of $[\mathrm{Na}]_{3}\left[\mathrm{Eu}(\mathrm{DPA})_{3}\right]$ with alkaline-earth salts $\left(\mathrm{CaCl}_{2}, \mathrm{MgCl}_{2}\right.$ and $\left.\mathrm{BaCl}_{2}\right)$ were undertaken independently. The slow diffusion of the divalent alkaline earth chloride solutions into an aqueous $[\mathrm{Na}]_{3}\left[\mathrm{Eu}(\mathrm{DPA})_{3}\right]$ solution results in the fast formation of transparent crystals, almost insoluble in water and organic solvent. Diffraction experiments performed on these crystals revealed the formation of structures of respective formula $\left(\mathrm{Mg}\left(\mathrm{H}_{2} \mathrm{O}\right)_{6}\right)_{3}\left[\mathrm{Eu}(\mathrm{DPA})_{3}\right]_{2} \cdot 7 \mathrm{H}_{2} \mathrm{O} \mathrm{1}$, 


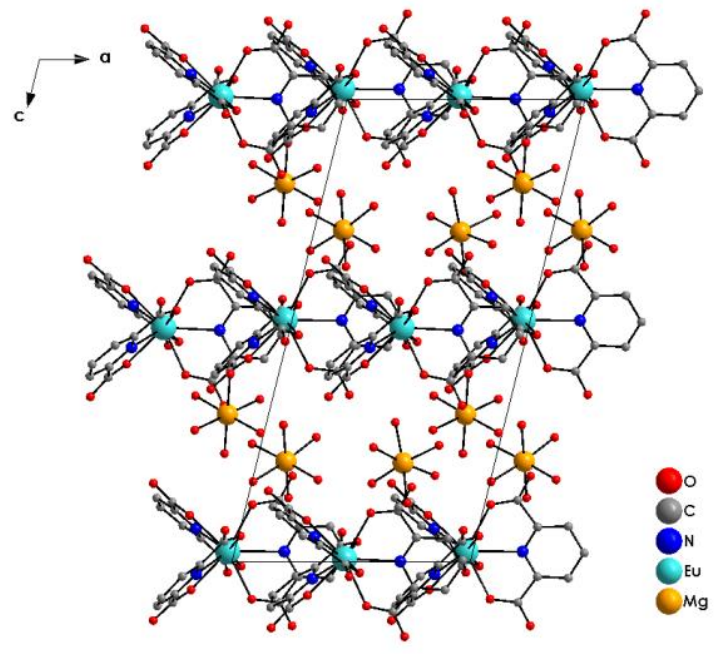

Figure 4. Projection along the b-axis of the crystal packing of 1.

$\left\{\left(\mathrm{Ca}\left(\mathrm{H}_{2} \mathrm{O}\right)_{4}\right)_{3}\left[\mathrm{Eu}(\mathrm{DPA})_{3}\right]_{2}\right\}_{\mathrm{n}} \cdot 11 \mathrm{nH}_{2} \mathrm{O} 2$ and of the previously reported $\left.\left\{\left[\mathrm{Eu}(\mathrm{DPA})_{3}\right]_{2} \mathrm{Ba}_{3}\left(\mathrm{H}_{2} \mathrm{O}\right)_{1} 6\right] 4 \mathrm{H}_{2} \mathrm{O}\right\}_{\mathrm{n}} \cdot{ }^{33,34-35}$ Crystal data and refinement parameters are given in Table S3, whereas selected bond lengths are compiled in Tables S4 and S6. In all cases, the $\mathrm{Na}^{+}$counter-ion was completely replaced by $\mathrm{Ca}^{2+} / \mathrm{Mg}^{2+} / \mathrm{Ba}^{2+}$ respectively, which are themselves coordinated by water or by $\left[\mathrm{Eu}(\mathrm{DPA})_{3}\right]^{3-}$ carboxylate forming 3-to-2 assemblies with the complex (Figures 4 and 5) and explaining the strong decrease of solubility. While the structure of 1 exhibits isolated $\left[\mathrm{Eu}(\mathrm{DPA})_{3}\right]^{3-}$ and $\left[\mathrm{Mg}\left(\mathrm{H}_{2} \mathrm{O}\right)_{6}\right]^{2+}$ units (Figure 4), 2 presents $3 \mathrm{D}$ network with $\left[\mathrm{Eu}(\mathrm{DPA})_{3}\right]^{3-}$ building blocks connected together through $\left[\mathrm{Ca}\left(\mathrm{H}_{2} \mathrm{O}\right)_{6}\right]^{2+}$ or $\left[\mathrm{Ca}\left(\mathrm{H}_{2} \mathrm{O}\right)_{8}\right]^{2+}$ bridges (Figures 5). In that latter case, second oxygen atom of one (for two ligands) or both (for one ligand) of the two DPA acid functions complete the $\mathrm{Ca}^{2+}$ environment and then creates links in the three directions between $\mathrm{Eu}$ (III) and $\mathrm{Ca}$ (II) complexes. The geometric configurations of both complexes were analyzed with the help of SHAPE2.1 program (Tables S5 and S7). The investigation of the precise configurations demonstrated that each $\mathrm{Eu}^{3+}$ cations environment within $\mathbf{1}$ and 2 structures fit well with the nona-coordinate capped square antiprism (CSAPR-9, $C_{4 v}$ ) and tricapped trigonal prism (TCTPR-9, $D_{3 h}$ ), respectively. All the Eu-O and Eu-N bond lengths are in good agreement with those observed in the literature. ${ }^{36-39}$

During automated crystallization experiments, we noticed that the characteristic red emission of $\left[\mathrm{Eu}(\mathrm{DPA})_{3}\right]^{3-}$ disappeared systematically for all the formulations containing transition metal ions (with $\mathrm{M}^{2+}=\mathrm{Cd}^{2+}, \mathrm{Zn}^{2+}, \mathrm{Ni}^{2+}, \mathrm{Fe}^{2+}, \mathrm{Co}^{2+}$ and mix). Measurements of the $[\mathrm{Na}]_{3}\left[\mathrm{Eu}(\mathrm{DPA})_{3}\right]$ emissions were performed in the presence of $\mathrm{MCl}_{2}$ in diluted water solution ([Ln] concentration at $1 \mathrm{mM}$, Figure S4). Interestingly, the luminescence of $\left[\mathrm{Eu}(\mathrm{DPA})_{3}\right]^{3-}$ was rapidly quenched after addition of 1 eq. of $\mathrm{MCl}_{2}$ and about $80 \%$ of the emission had disappeared. This competition experiment has also been performed at a concentration closer to the crystallization conditions: slow diffusion of a $\mathrm{CuCl}_{2}$ solution $(50 \mathrm{mM})$ in $[\mathrm{Na}]_{3}\left[\mathrm{Eu}(\mathrm{DPA})_{3}\right](50 \mathrm{mM})$ led to the formation of crystals of $\left\{\mathrm{Cu}(\mathrm{DPA})\left(\mathrm{H}_{2} \mathrm{O}\right)_{2}\right\}_{\mathrm{n}} 3$ suitable for X-rays diffraction analysis (Figure 6 and Tables S3 and S8). $\mathrm{Cu}$ (II) is coordinated to one deprotonated ligand (two oxygen and one nitrogen atoms) and two water molecules. The distorted cation octahedral $\mathrm{ML}_{6}$ $\left\{\mathrm{O}_{5} \mathrm{~N}_{1}\right\}$ environment is then completed by one oxygen atom (O3) belonging to one neighboring complex unit. This bridge leads to the formation of chains of complexes running along the $c$-axis of the unit-cell with a $\mathrm{Cu}^{2+} \ldots \mathrm{Cu}^{2+}$ intra-chain distance equals to $3.87 \AA$. All the $\mathrm{Cu}-\mathrm{N}, \mathrm{Cu}-\mathrm{O}$ bond lengths and $\mathrm{O}-\mathrm{Cu}-$ $\mathrm{O}, \mathrm{N}-\mathrm{Cu}-\mathrm{O}$ bond angles are in agreement with those usually listed in the literature for corresponding systems. ${ }^{40}$ $\left\{\mathrm{Cu}(\mathrm{DPA})\left(\mathrm{H}_{2} \mathrm{O}\right)_{2}\right\}_{\mathrm{n}}$ chains perfectly stack one above the others in the $a$-direction of the unit-cell and slightly shifted in the $c$ direction of the unit-cell. Structural cohesion between chains is assumed by weak interactions (hydrogen bonds and Van der Walls interactions). These results indicated that a transmetalation reaction occurs very rapidly between $\left[\mathrm{Eu}(\mathrm{DPA})_{3}\right]^{3-}$ and transition metal cations leading to the destruction of the lanthanide complex in solution.

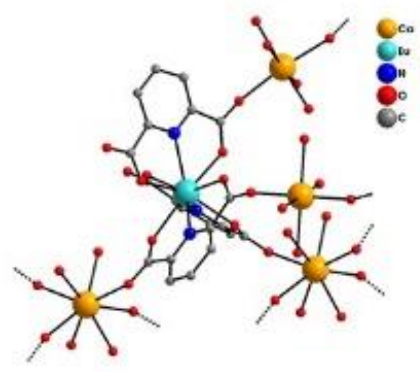

(a)

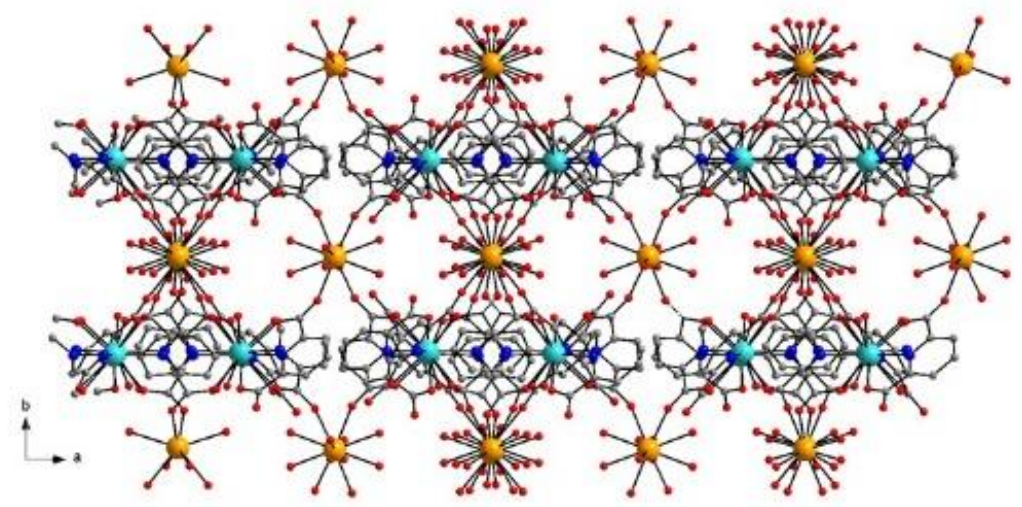

(b)

Figure 5. (a) molecular building block of $\left\{\left(\mathrm{Ca}\left(\mathrm{H}_{2} \mathrm{O}\right)_{4}\right)_{3}\left[\mathrm{Eu}(\mathrm{DPA})_{3}\right]_{2}\right\}_{\mathrm{n}} \cdot 11 \mathrm{nH}_{2} \mathrm{O}$ complex 2; (b) projection along the $c$-axis of the unitcell in order to highlight $\left[\mathrm{Ca}\left(\mathrm{H}_{2} \mathrm{O}\right)_{\mathrm{n}}\right]^{2+}$ (in orange) and $\left[\mathrm{Eu}(\mathrm{DPA})_{3}\right]^{3-}$ (in blue) planes running perpendicularly to the $b$-axis of the unitcell. For clarity, hydrogen atoms and non-coordinated water molecules have been removed. 


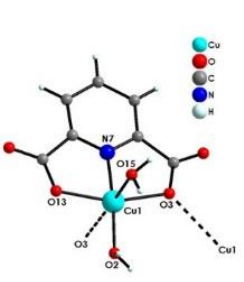

(a)

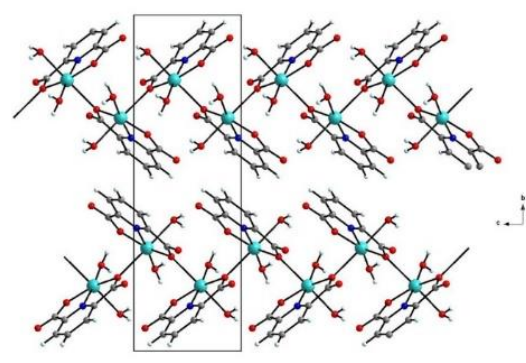

(b)
Figure 7. (a) molecular unit of $\mathbf{3}$ with important labels; (b) projection along the $a$-axis of the unit-cell of $\left\{\mathrm{Cu}(\mathrm{DPA})\left(\mathrm{H}_{2} \mathrm{O}\right)_{2}\right\}_{\mathrm{n}}$ chains running along the $c$-axis of the unitcell.

The behavior of the Tb-Xo4 complex is completely different. The automated crystallization experiments revealed that all drops remained perfectly clear at $10 \mathrm{mM}$ concentration. At 100 $\mathrm{mM}$, only 3 conditions over 576 led to the formation of microcrystalline precipitate (Figures S1-3). These conditions contain among other ammonium fluoride, calcium acetate or ammonium sulfate in the presence of polyethylene glycol. The obtained microcrystals did not present optimal quality for X-ray diffraction and we have been unable to reproduce them in larger batch for the preparation of well diffracting crystals. TbXo4 crystals of global formula $\left[\mathrm{Tb}_{4} \mathrm{~L}_{4}\left(\mathrm{H}_{2} \mathrm{O}\right)_{4}\right] \mathrm{Cl}_{4} \cdot 15 \mathrm{H}_{2} \mathrm{O}$ (4) were hardly obtained from slow evaporation of a water/acetonitrile mixture (Tables S3, S9 and S10). These crystals are luminescent in the green upon UV irradiation (Figure 8). In the structure, one $\mathrm{Tb}(\mathrm{III})$ atom is coordinated in a $\left\{\mathrm{N}_{5} \mathrm{O}_{4}\right\}$ environment. The deprotonated ligand $\mathrm{L}^{2-}$ is coordinated by two oxygen atoms from the carboxylate moieties and five nitrogen ones from the pyridine and the triazacyclononane macrocycle $\mathrm{The} \mathrm{Tb}-\mathrm{O}$ bond lengths $(2.403 \AA)$ are shorter than Tb-N ones $(2.566 \AA)$ and are in good agreement with those previously reported in the literature for identical complexes. ${ }^{41}$ The coordination sphere is completed by the two oxygen atoms from one water molecule with Tb-O bond length (2.449 $\AA$ ) comparable to other Tb-O(L) ones and one oxygen atom from the carbonyl fragment belonging to the ligand of a neighboring complex with a short Tb-O bond $(2.265 \AA)$. Thus, four complexes assemble in a remarkable tetrameric supramolecular architecture (Figure 8). The charge balance is ensured by the presence of four $\mathrm{Cl}^{-}$anions within the unit-cell. Fifteen non-coordinated water molecules also co-crystallize within the unit-cell. Both of these noncoordinated molecules or anions are located in canals running along the $c$-axis of the unit-cell and generated by the global complexes packing.

In addition, the stability experiments in solution have been performed with $\mathrm{Tb}$-Xo4, in the same conditions than those with $[\mathrm{Na}]_{3}\left[\mathrm{Eu}(\mathrm{DPA})_{3}\right]$. Firstly, addition of 1 eq. of $\mathrm{MCl}_{2}$ to a $\mathrm{Tb}-\mathrm{Xo} 4$ solution led to a much slower decrease of the green luminescence observed over several days (Figure S5) compared to the almost instantaneous luminescence decrease observed $[\mathrm{Na}]_{3}\left[\mathrm{Eu}(\mathrm{DPA})_{3}\right]$ (Figure S4). Secondly, in the presence of alkaline-earth salts $\left(\mathrm{MgCl}_{2}, \mathrm{CaCl}_{2}, \mathrm{BaAc}_{2} 1-10 \mathrm{eq}\right)$, no variation of the luminescence intensity of $\mathrm{Tb}-\mathrm{Xo} 4$ was observed for days (Figure S6). All results indicated that a trans-metalation reaction occurs between the two lanthanide complexes and transition metal cations but with a very different kinetic underlining a higher stability for the macrocyclic Tb-Xo4 complex. In addition, in the presence of alkaline-earth salts, TbXo4 is highly stable whereas $\left[\mathrm{Eu}(\mathrm{DPA})_{3}\right]^{3-}$ precipitates and/or self-crystallizes.

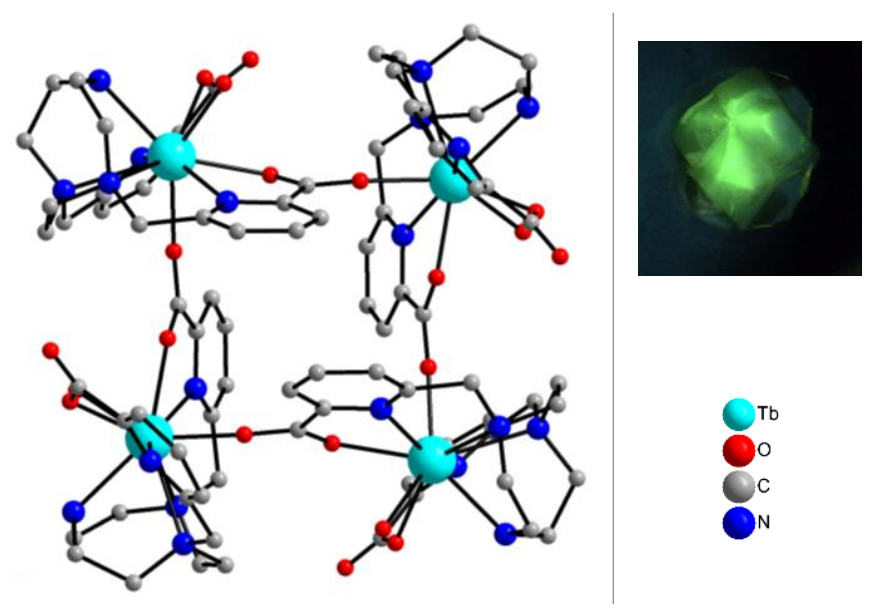

Figure 8. Structure of complex 4. For clarity, hydrogen atoms and non-coordinated chloride and water molecules have been removed. In inset is reported the picture of one crystal of complex 4 under UV irradiation $\left(\lambda_{\mathrm{ex}}=254 \mathrm{~nm}\right)$.

\section{Conclusion.}

In conclusion, in this article we started undertaking the systematic analysis of the influence of the commercial crystallization kit composition on the efficiency of two lanthanide based additives: $[\mathrm{Na}]_{3}\left[\mathrm{Eu}(\mathrm{DPA})_{3}\right]$ and $\mathrm{Tb}-\mathrm{Xo} 4$. This study reveals that the tris-dipicolinate complex presents a lower chemical stability and a strong tendency to self-crystallization detrimental for its use in high-throughput robotized crystallization platform. On the other hand, the $\mathrm{Tb}-\mathrm{Xo} 4$ is perfectly soluble in the crystallization media, stable in the presence of alkaline-earth dications and slowly decomposed (within days) by trans-metalation with transition metals. This article also revealed the potential positive of interactions between the crystallization mixture component and $\mathrm{Tb}-\mathrm{Xo} 4$ leading to the formation of more complex adducts like $\left\{\right.$ AdkA/Tb-Xo4/ $\left.\mathrm{Mg}^{2+} / \mathrm{GOL}\right\}$ or $\left\{\mathrm{FprA} / \mathrm{Tb}-\mathrm{Xo} 4 / \mathrm{Ca}^{2+} / \mathrm{GOL}\right\}$ in the protein binding sites. The observation of such multicomponents adducts illustrated the complexity and versatility of the supramolecular chemistry occurring at the surface of proteins. The role of such adducts during the crystallization process is currently under investigation.

\section{Acknowledgements.}

Authors acknowledge the Fondation Maison de la Chimie, Agence Nationale de la Recherche (ANR Ln23-13-BS07-000701) and SATT Pulsalys for grants to AR, SE and SDP and Region AuRA for financial support (program Xo4-2.0 and R\&D booster Crystfrag) . Authors also thank the Polyvalan Company for its help and the pôle de compétitivite LyonBiopôle. 
Keywords. Protein crystallography • lanthanide complexes • triazacyclononane $\bullet$ picolinate

\section{References.}

1. Terwilliger, T. C.; Stuart, D.; Yokoyama, S., Lessons from Structural Genomics. Annual Rev. Biophys. 2009, 38 (1), 371-383.

2. Khurshid, S.; Saridakis, E.; Govada, L.; Chayen, N. E., Porous nucleating agents for protein crystallization. Nat. Protoc. 2014, 9 (7), 1621-1633.

3 McPherson, A.; Gavira J.; Introduction to protein crystallization, Acta Crystallogr F Struct Biol Commun. 2014 70, 2 20.

4. $\quad$ Santarsiero, B. D.; Yegian, D. T.; Lee, C. C.; Spraggon, G.; Gu, J.; Scheibe, D.; Uber, D. C.; Cornell, E. W.; Nordmeyer, R. A.; Kolbe, W. F.; Jin, J.; Jones, A. L.; Jaklevic, J. M.; Schultz, P. G.; Stevens, R. C., An approach to rapid protein crystallization using nanodroplets. J. Appl. Crystallogr. 2002, 35, 278-281.

5. Brown, J.; Walter, T. S.; Carter, L.; Abrescia, N. G. A.; Aricescu, A. R.; Batuwangala, T. D.; Bird, L. E.; Brown, N.; Chamberlain, P. P.; Davis, S. J.; Dubinina, E.; Endicott, J.; Fennelly, J. A.; Gilbert, R. J. C.; Harkiolaki, M.; Hon, W. C.; Kimberley, F.; Love, C. A.; Mancini, E. J.; Manso-Sancho, R.; Nichols, C. E.; Robinson, R. A.; Sutton, G. C.; Schueller, N.; Sleeman, M. C.; Stewart-Jones, G. B.; Vuong, M.; Welburn, J.; Zhang, Z.; Stammers, D. K.; Owens, R. J.; Jones, E. Y.; Harlos, K.; Stuart, D. I., A procedure for setting up highthroughput nanolitre crystallization experiments. II. Crystallization results. J. Appl. Crystallogr. 2003, 36, 315-318.

6. Hendrickson, W. A., Anomalous diffraction in crystallographic phase evaluation. Quarterly Reviews of Biophysics 2014, 47 (1), 49-93.

7. Doublié, S., Preparation of selenomethionyl proteins for phase determination. In Methods Enzymol., Academic Press: 1997; Vol. 276, pp 523-530.

8. D'Arcy, A.; Mac Sweeney, A.; Haber, A., Using natural seeding material to generate nucleation in protein crystallization experiments. Acta Crystallogr. Section D-Biol. Crystallogr. 2003, 59, $1343-1346$.

9. Georgieva, D. G.; Kuil, M. E.; Oosterkamp, T. H.; Zandbergen, H. W.; Abrahams, J. P., Heterogeneous nucleation of three-dimensional protein nanocrystals. Acta Crystallogr. Section DBiol.Crystallogr. 2007, 63, 564-570.

10. Saridakis, E.; Khurshid, S.; Govada, L.; Phan, Q.; Hawkins, D.; Crichlow, G. V.; Lolis, E.; Reddy, S. M.; Chayen, N. E., Protein crystallization facilitated by molecularly imprinted polymers. Proc. Nat. Ac. Sci. 2011, 108 (27), 11081.

11. Khurshid, S.; Govada, L.; El-Sharif, H. F.; Reddy, S. M.; Chayen, N. E., Automating the application of smart materials for protein crystallization. Acta Crystallogr. Section D-Struct.Biol.2015, 71, 534-540.

12. Bijelic, A.; Rompel, A., The use of polyoxometalates in protein crystallography - An attempt to widen a well-known bottleneck. Coord. Chem. Rev. 2015, 299, 22-38.

13. Breibeck, J.; Bijelic, A.; Rompel, A., Transition metalsubstituted Keggin polyoxotungstates enabling covalent attachment to proteinase K upon co-crystallization. Chem Commun 2019, 55 (77), $11519-11522$

14. Mac Sweeney, A.; Chambovey, A.; Wicki, M.; Muller, M.; Artico, N.; Lange, R.; Bijelic, A.; Breibeck, J.; Rompel, A., The crystallization additive hexatungstotellurate promotes the crystallization of the HSP70 nucleotide binding domain into two different crystal forms. PLoS One 2018, 13 (6), e0199639.

15. Bijelic, A.; Rompel, A., Polyoxometalates: more than a phasing tool in protein crystallography. ChemTexts 2018, 4 (3), 10.

16. McGovern, R. E.; Fernandes, H.; Khan, A. R.; Power, N. P.; Crowley, P. B., Protein camouflage in cytochrome c-calixarene complexes. Nat Chem 2012, 4 (7), 527-33.
17. McGovern, R. E.; Feifel, S. C.; Lisdat, F.; Crowley, P. B., Microscale Crystals of Cytochrome $\mathrm{c}$ and Calixarene on Electrodes: Interprotein Electron Transfer between Defined Sites. Angew. Chem. Int. Ed. 2015, 54 (21), 6356-9.

18. Guagnini, F.; Antonik, P. M.; Rennie, M. L.; O'Byrne, P.; Khan, A. R.; Pinalli, R.; Dalcanale, E.; Crowley, P. B., Cucurbit[7]urilDimethyllysine Recognition in a Model Protein. Angew. Chem., Int. Ed. 2018, 57 (24), 7126-7130.

19. Engilberge, S.; Rennie, M. L.; Dumont, E.; Crowley, P. B., Tuning Protein Frameworks via Auxiliary Supramolecular Interactions. ACS Nano 2019, 13 (9), 10343-10350.

20. Pompidor, G.; D'Aleo, A.; Vicat, J.; Toupet, L.; Giraud, N.; Kahn, R.; Maury, O., Protein crystallography through supramolecular interactions between a lanthanide complex and arginine. Angew. Chem. Int. Ed. 2008, 47 (18), 3388-91.

21. Talon, R.; Kahn, R.; Dura, M. A.; Maury, O.; Vellieux, F. M.; Franzetti, B.; Girard, E., Using lanthanoid complexes to phase large macromolecular assemblies. J Synchrotron Radiat 2011, 18 (1), 74-8. 22. Engilberge, S.; Riobe, F.; Di Pietro, S.; Lassalle, L.; Coquelle, N.; Arnaud, C. A.; Pitrat, D.; Mulatier, J. C.; Madern, D.; Breyton, C.; Maury, O.; Girard, E., Crystallophore: a versatile lanthanide complex for protein crystallography combining nucleating effects, phasing properties, and luminescence. Chem Sci 2017, 8 (9), 5909-5917.

23. Engilberge, S.; Wagner, T.; Santoni, G.; Breyton, C.; Shima, S.; Franzetti, B.; Riobe, F.; Maury, O.; Girard, E., Protein crystal structure determination with the crystallophore, a nucleating and phasing agent. J. Appl. Crystallogr. 2019, 52 (Pt 4), 722-731.

24. de Wijn, R.; Hennig, O.; Roche, J.; Engilberge, S.; Rollet, K.; Fernandez-Millan, P.; Brillet, K.; Betat, H.; Morl, M.; Roussel, A.; Girard, E.; Mueller-Dieckmann, C.; Fox, G. C.; Olieric, V.; Gavira, J. A.; Lorber, B.; Sauter, C., A simple and versatile microfluidic device for efficient biomacromolecule crystallization and structural analysis by serial crystallography. IUCrJ 2019, 6 (Pt 3), 454-464.

25. Rempel, S.; Colucci, E.; de Gier, J. W.; Guskov, A.; Slotboom, D. J., Cysteine-mediated decyanation of vitamin B12 by the predicted membrane transporter BtuM. Nat. Comm. 2018, 9 (1), 3038. 26. Hajj Chehade, M.; Pelosi, L.; Fyfe, C. D.; Loiseau, L.; Rascalou, B.; Brugière, S.; Kazemzadeh, K.; Vo, C.-D.-T.; Ciccone, L.; Aussel, L.; Couté, Y.; Fontecave, M.; Barras, F.; Lombard, M.; Pierrel, F., A Soluble Metabolon Synthesizes the Isoprenoid Lipid Ubiquinone. Cell Chem. Biol. 2019, 26 (4), 482-492.e7.

27. Roche, J.; Girard, E.; Mas, C.; Madern, D., The archaeal LDH-like malate dehydrogenase from Ignicoccus islandicus displays dual substrate recognition, hidden allostery and a non-canonical tetrameric oligomeric organization. J. Struct. Biol. 2019, 208 (1), 7-17. 28. Schada von Borzyskowski, L.; Severi, F.; Krüger, K.; Hermann, L.; Gilardet, A.; Sippel, F.; Pommerenke, B.; Claus, P.; Cortina, N. S.; Glatter, T.; Zauner, S.; Zarzycki, J.; Fuchs, B. M.; Bremer, E.; Maier, U. G.; Amann, R. I.; Erb, T. J., Marine Proteobacteria metabolize glycolate via the $\beta$-hydroxyaspartate cycle. Nature 2019, 575 (7783), 500-504.

29. Belot, L.; Ouldali, M.; Roche, S.; Legrand, P.; Gaudin, Y.; Albertini, A. A., Crystal structure of Mokola virus glycoprotein in its post-fusion conformation. PLOS Pathogens 2020, 16 (3), e1008383.

30. Bernhardsgrütter, I.; Vögeli, B.; Wagner, T.; Peter, D. M.; Cortina, N. S.; Kahnt, J.; Bange, G.; Engilberge, S.; Girard, E.; Riobé, F.; Maury, O.; Shima, S.; Zarzycki, J.; Erb, T. J., The multicatalytic compartment of propionyl-CoA synthase sequesters a toxic metabolite. Nat. Chem. Biol.2018, 14 (12), 1127-1132.

31. Vogeli, B.; Engilberge, S.; Girard, E.; Riobe, F.; Maury, O.; Erb, T. J.; Shima, S.; Wagner, T., Archaeal acetoacetyl-CoA thiolase/HMG-CoA synthase complex channels the intermediate via a fused CoA-binding site. Proc Natl Acad Sci 2018, 115 (13), 3380-3385. 32. Engilberge, S.; Riobe, F.; Wagner, T.; Di Pietro, S.; Breyton, C.; Franzetti, B.; Shima, S.; Girard, E.; Dumont, E.; Maury, O., Unveiling the Binding Modes of the Crystallophore, a Terbium-based 
Nucleating and Phasing Molecular Agent for Protein Crystallography. Chem. Eur; J. 2018, 24 (39), 9739-9746.

33. Zhao, X.-Q.; Zuo, Y.; Gao, D.-L.; Zhao, B.; Shi, W.; Cheng, P., Syntheses, Structures, and Luminescence Properties of a Series of LnIII-BaIIHeterometal-Organic Frameworks. Cryst. Growth \& Des. 2009, 9 (9), 3948-3957.

34. Chen, Y.; Li, L.; Zhang, Q.; Liu, S.; Tian, Z.; Ju, Z., Effects of calcium ions on crystal structure and luminescence properties of six rare earth metal complexes. J. Solid State Chem. 2020, 281, 121053.

35. Chen, Y.; Zhao, X.; Gao, R.; Ruan, Z.; Lin, J.; Liu, S.; Tian, Z.; Chen, X., Temperature-induced solvent assisted single-crystal-tosingle-crystal transformation of $\mathrm{Mg}$ (II)- $\mathrm{Ln}$ (III) heterometallic coordination polymers. J. Solid State Chem. 2020, 292, 121674.

36. Tancrez, N.; Feuvrie, C.; Ledoux, I.; Zyss, J.; Toupet, L.; Le Bozec, H.; Maury, O., Lanthanide Complexes for Second Order Nonlinear Optics: Evidence for the Direct Contribution of $\mathrm{f}$ Electrons to the Quadratic Hyperpolarizability. J. Am. Chem. Soc. 2005, 127 (39), 13474-13475.

37. D'Aleo, A.; Pompidor, G.; Elena, B.; Vicat, J.; Baldeck, P. L.; Toupet, L.; Kahn, R.; Andraud, C.; Maury, O., Two-photon microscopy and spectroscopy of lanthanide bioprobes. Chemphyschem 2007, 8 (14), 2125-32.

38. D'Aléo, A.; Toupet, L.; Rigaut, S.; Andraud, C.; Maury, O., Guanidinium as powerful cation for the design of lanthanate trisdipicolinate crystalline materials: Synthesis, structure and photophysical properties. Opt. Mater. 2008, 30 (11), 1682-1688.

39. Mooibroek, T. J.; Gamez, P.; Pevec, A.; Kasunic, M.; Kozlevcar, B.; Fu, W. T.; Reedijk, J., Efficient, stable, tunable, and easy to synthesize, handle and recycle luminescent materials: [H2NMe2]3[Ln(III)(2,6-dipicolinolate)3] $(\mathrm{Ln}=\mathrm{Eu}, \mathrm{Tb}$, or its solid solutions). Dalton Trans 2010, 39 (28), 6483-7.

40. Sileo, E. E.; Rigotti, G.; Rivero, B. E.; Blesa, M. A., Kinetic study of the thermal dehydration of copper(II) dipicolinates: Crystal and molecular structure of $\mathrm{Cu}$ (II) (Pyridine 2,6-Dicarboxylato) DI- and Trihydrated. J. Phys. Chem. Solids 1997, 58 (7), 1127-1135.

41. Nocton, G.; Nonat, A.; Gateau, C.; Mazzanti, M., Water Stability and Luminescence of Lanthanide Complexes of Tripodal Ligands Derived from 1,4,7-Triazacyclononane: Pyridinecarboxamide versus Pyridinecarboxylate Donors. Helv. Chim. Acta 2009, 92 (11), 2257-2273. 


\section{Influence of divalent cations in the protein crystallisation process assisted by Lanthanide-based additives.}

Amandine Roux, ${ }^{[a, b]}$ Romain Talon, ${ }^{[c]}$ Zaynab Alsalman, ${ }^{[c]}$ Sylvain Engilberge, ${ }^{[c]}$ Anthony D'Aléo, ${ }^{[a]}$

Sebastiano Di Pietro, ${ }^{[a]}$ Adeline Y. Robin, ${ }^{[c]}$ Alessio Bartocci, ${ }^{[a]}$ Guillaume Pilet, ${ }^{[d]}$ Elise Dumont, ${ }^{[a, e]}$ Tristan Wagner, ${ }^{[\mathrm{f}, \mathrm{g}]}$ Seigo Shima, ${ }^{[\mathrm{f}]}$ François Riobé, ${ }^{[\mathrm{a}] \star}$ Eric Girard, ${ }^{[\mathrm{c}] *}$ Olivier Maury. ${ }^{[\mathrm{a}] *}$

a] Univ Lyon, ENS de Lyon, CNRS UMR 5182, Université Claude Bernard Lyon 1, Laboratoire de Chimie, F-69342 Lyon, France.

E-mail: olivier.maury@ens-lyon.fr, francois.riobe@ens-lyon.fr,

[b] Polyvalan F-69342 Lyon, France

[c] Univ Grenoble Alpes, CEA, CNRS, IBS, F-38000 Grenoble, France.

E-mail: eric.girard@ibs.fr.

[d] Univ de Lyon, CNRS UMR 5615, Université Claude Bernard Lyon 1, 43 boulevard du 11 novembre 1918, F-69622 Villeurbanne cedex.

[e] Institut Universitaire de France, 1 rue Descartes, 75005 Paris

[f] Microbial Protein Structure Group, Max Planck Institute for Terrestrial Microbiology, Karl-vonFrisch-Str. 10, D-35043 Marburg, Germany

[g] Microbial Metabolism Group, Max Planck Institute for Marine Microbiology, 1-Celsiusstrasse, 35043 Bremen, Germany 


\section{1) Lanthanide complex syntheses}

Starting reagents were purchased from Sigma-Aldrich or Acros and used without further purification. All organic solvents were dried on molecular sieves for $48 \mathrm{~h}$.

Synthesis of the complexes $[\mathrm{Na}]_{3}\left[\mathrm{Eu}(\mathrm{DPA})_{3}\right]^{\text {i, }}$ and $\mathrm{Tb}-\mathrm{Xo} 4^{\mathrm{i} \text { iiii }}$ have been previously described Both complexes are now commercially available by Polyvalan company.

\section{2) Protein production and crystallization}

The Ec-AcrB (Acriflavine resistant protein B from Escherichia coli) overexpression vector is a gift of K.M. Pos. Ec-AcrB production and purification were performed as described in the literature. ${ }^{\text {iv }}$ Prior to crystallization assays, Ec-AcrB was concentrated to $10 \mathrm{mg}^{-\mathrm{ml}^{-1}}$ in $10 \mathrm{mM}$ HEPES pH $7.0,0.02 \%$ ndodecyl- $\beta$-D-maltopyranoside (DDM). Crystallization of Ec-AcrB in the presence and in the absence of $[\mathrm{Na}]_{3}\left[\mathrm{Eu}(\mathrm{DPA})_{3}\right]$ was performed according to the protocol used for the self-crystallization evaluation of $[\mathrm{Na}]_{3}\left[\mathrm{Eu}(\mathrm{DPA})_{3}\right]$.

Production of adenylate kinase (AdkA) protein from Methanothermococcus thermolithotrophicus as well as crystallization in the presence of $\mathrm{Tb}-\mathrm{Xo} 4$ was performed as indicated in the literature. ${ }^{v}$

\section{3) Computational details.}

In order to estimate the interaction energies for $\mathrm{Tb}-\mathrm{Xo} 4$ at AdkA binding site, we started from the PDB structure obtained for AdkA co-crystallized with Tb-Xo4 (PDB ID 6HF7), and resort to density functional theory (DFT) calculations to situate the energetic contributions of each residues or molecule involved in the binding site of AdkA. The computational protocol was identical to the one used in a previous publication $^{\text {vi }}$ for 6 proteins co-crystallized with $\mathrm{Tb}$-Xo4, namely after addition of relevant hydrogens based on a PropKa analysis ${ }^{\text {vii }}$ and corroborated by chemical inspection, a geometry optimization of the cluster embracing the Tb-Xo4 complex, the glycerol molecule, the aspartate $\mathrm{D} 90_{\mathrm{C}}$, with the bridging magnesium ion and its five coordinated water molecules, all present in the X-ray structure was performed at the B3LYP-D3BJ/6-31G(d,p) level of theory. The Stuttgart/Dresden SDD pseudo-potential was used for the terbium atom. The calculations were performed with the Gaussian16 Rev B.01 series of programs. viii We then extracted interaction energies based on the cluster represented in Figure S7, which reflect the contribution of each residue in a static framework at $0 \mathrm{~K}$. An implicit continuum model was used (IEFPCM as available in Gaussian16) with an effective dielectric constant of 8.0 to account for the electrostatic embedding of the protein. 


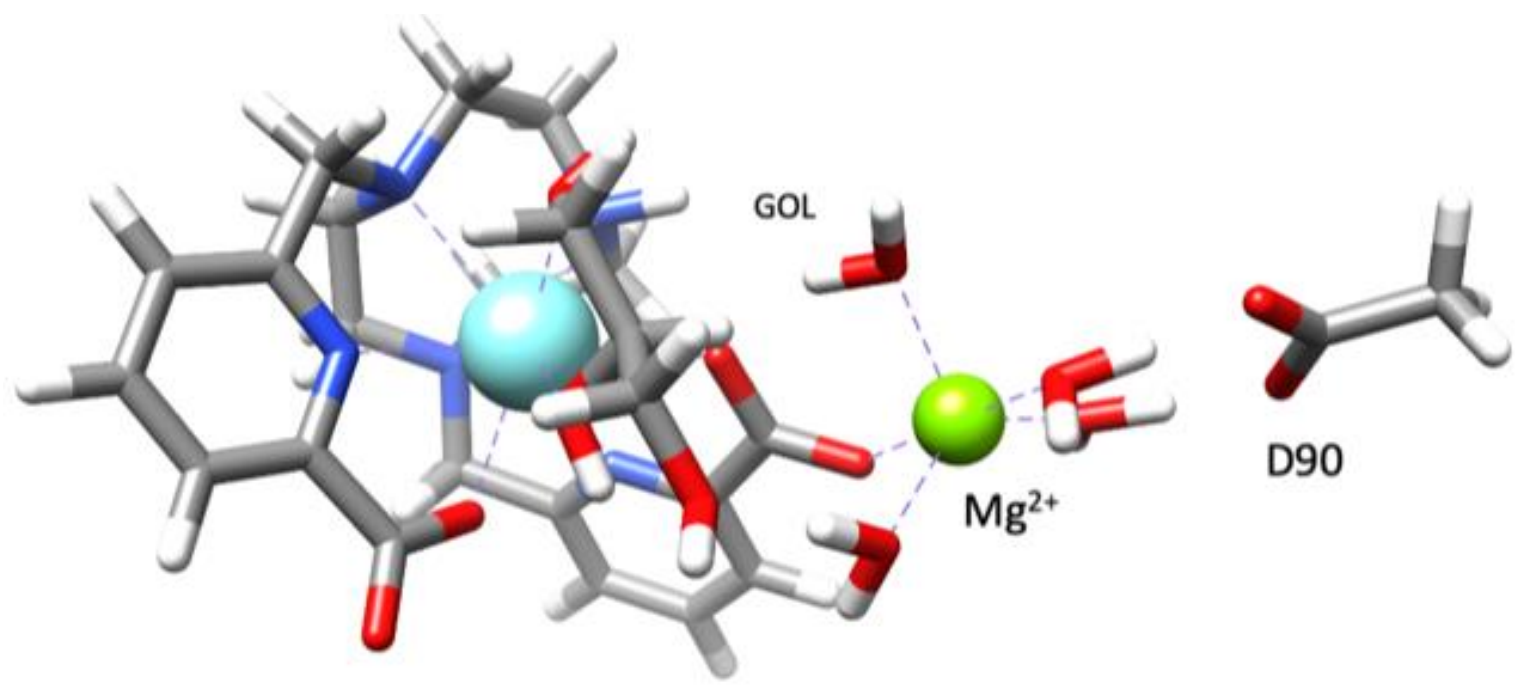

Figure S1. Cluster of $\mathrm{Tb}-\mathrm{Xo} 4$, interacting with a glycerol molecule, as well as $\mathrm{Mg}^{2+}$ and the aspartate D90. The four water molecules were taken from the crystallographic positions of their oxygen atoms. Residue D90 was capped by a methyl group, and the $\mathrm{C} \square$ atoms were maintained in their crystallographic position.

Table S1. Interaction energies estimated at the DFT/B3LYP-6-31+G(d,p)/SDD level of theory, as well as characteristic distances. (*) The distances between oxygen atoms of the four water molecules and the central magnesium atom range between 1.99 and $2.09 \AA$.

\begin{tabular}{|l|c|c|}
\hline Residues & Distances $(\AA)$ & Interaction energies $\left(\mathrm{kcal}^{\AA} \mathrm{mol}^{-1}\right)$ \\
\hline Glycerol & $2.51,2.51$ & -27.8 \\
\hline $\mathrm{D} 90$ & $1.52,1.53$ & -9.3 \\
\hline$\left\{\mathrm{Mg}^{2+}+4 \mathrm{H}_{2} \mathrm{O}+\mathrm{D} 90\right\}$ & $2.09\left(^{*}\right)$ & -25.3 \\
\hline & & \\
\hline
\end{tabular}

\section{4) Self-crystallization evaluation}

Prior to automated crystallization experiments, the lanthanide complex powder was directly dissolved in milliQ water to reach the required concentration $\left(25 \mathrm{mM}\right.$ and $100 \mathrm{mM}$ for $[\mathrm{Na}]_{3}\left[\mathrm{Eu}(\mathrm{DPA})_{3}\right]$ and $10 \mathrm{mM}$ and $100 \mathrm{mM}$ for $\mathrm{Tb}-\mathrm{Xo} 4)$.

All automated screening trials were done at the High-Throughput Crystallization Laboratory (HTXlab) platform (EMBL Grenoble). The crystallization experiments were set up by mixing a volume of lanthanide complex solution with an equal volume of precipitant solution to form the crystallization drops. Storage (at 293K) and crystallization drops inspection were ensured automatically by the imaging system available at the HTXlab. We selected standard commercial crystallization kits as proposed by the HTXlab for initial screening, for a total of 576 conditions. 
The kits used for self-crystallization evaluation of Tb-Xo4 and $[\mathrm{Na}]_{3}\left[\mathrm{Eu}(\mathrm{DPA})_{3}\right]$ are detailed in Tables $\mathrm{S} 1$ and $\mathrm{S} 2$.

Table S2. Commercial crystallization kits used with $[\mathrm{Na}]_{3}\left[\mathrm{Eu}(\mathrm{DPA})_{3}\right]$ (*Kits containing divalent ions) Screen 1 Hampton Research Crystal Screen I \& II*

\begin{tabular}{l|l|l}
\hline Screen 2 & Hampton Research & Crystal Screen lite \& PEG/Ion* \\
\hline Screen 3 & Qiagen & MembFac \& Natrix* \\
\hline Screen 4 & Qiagen & Quick Screen \& grid screens sulfate, formate, malonate \\
\hline Screen 5 & Hampton Research & Grid Screen PEG 6K, PEG/LiCl, MPD - Screen Mme \\
\hline Screen 6 & Hampton Research & Index Screen* \\
\hline
\end{tabular}

Table S3. Commercial crystallization kits used with Tb-Xo4 (*Kits containing divalent ions)

\begin{tabular}{l|l|l} 
Screen 1 & Qiagen/Nextal & \multicolumn{1}{l}{ The Classics Suite* } \\
\hline Screen 2 & Molecular dimensions & JCSG+* \\
\hline Screen 3 & Molecular dimensions & PACT premier* \\
\hline Screen 4 & Qiagen/Nextal & PEGs-I* \\
\hline Screen 5 & Hampton Research & Grid Screen Salt \\
\hline Screen 6 & Rigaku Reagents & Wizard I \& II* \\
\hline
\end{tabular}




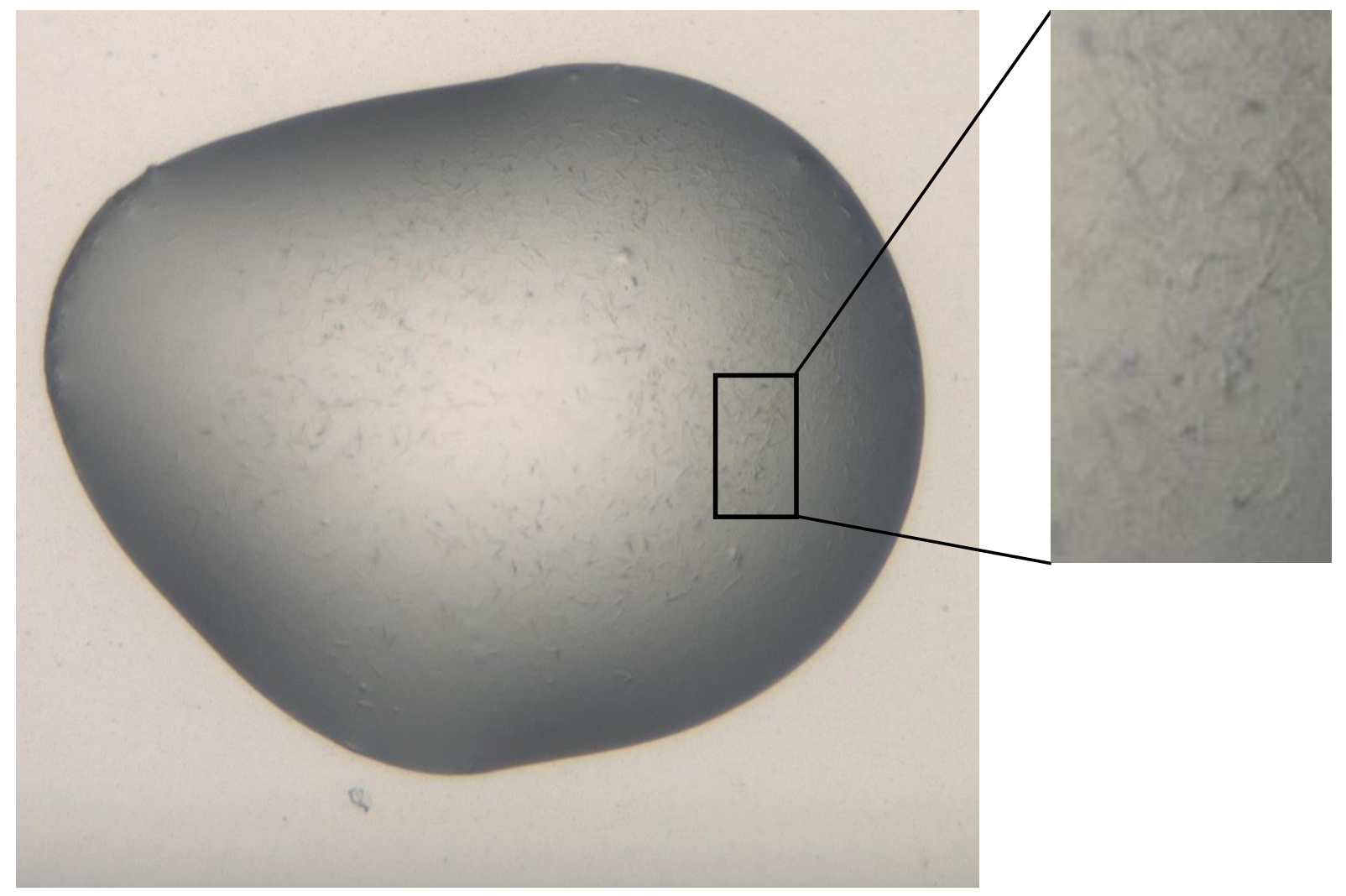

Figure S2. Self-crystallization or precipitation of Tb-Xo4 (at $0.1 \mathrm{M}$ concentration) during automated HTX experiments in the following condition: crystallization kit PEGs-I; condition E3; composition: ammonium fluoride 0.2M, PEG 3350 20\%.

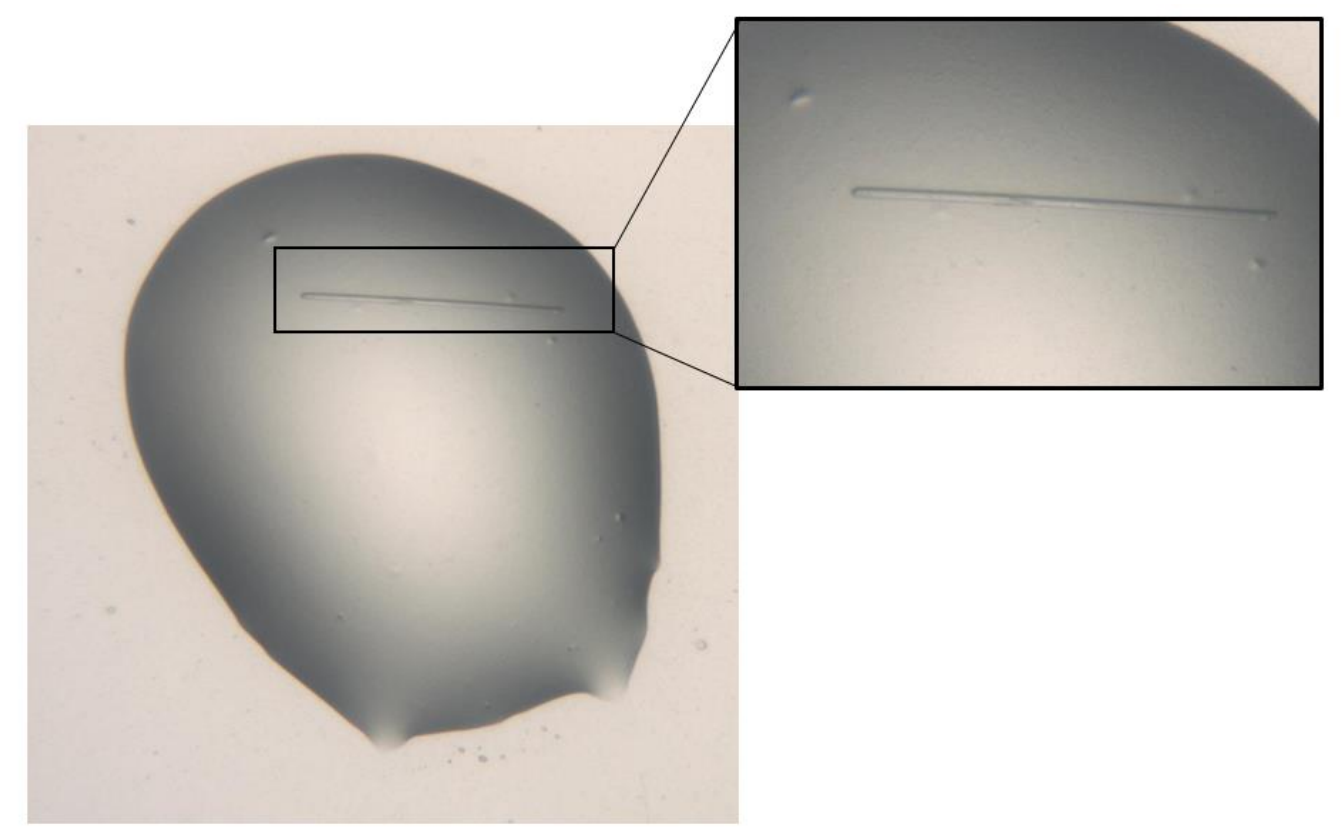

Figure S3. Self-crystallization of $\mathrm{Tb}-\mathrm{Xo} 4$ (at $0.1 \mathrm{M}$ concentration) during automated HTX experiments in the following condition: crystallization kit JCSG; condition D10; composition: calcium acetate hydrate $0.2 \mathrm{M}$, sodium cacodylate $0.1 \mathrm{M}$, pH 6.5, PEG 300 40\%. 


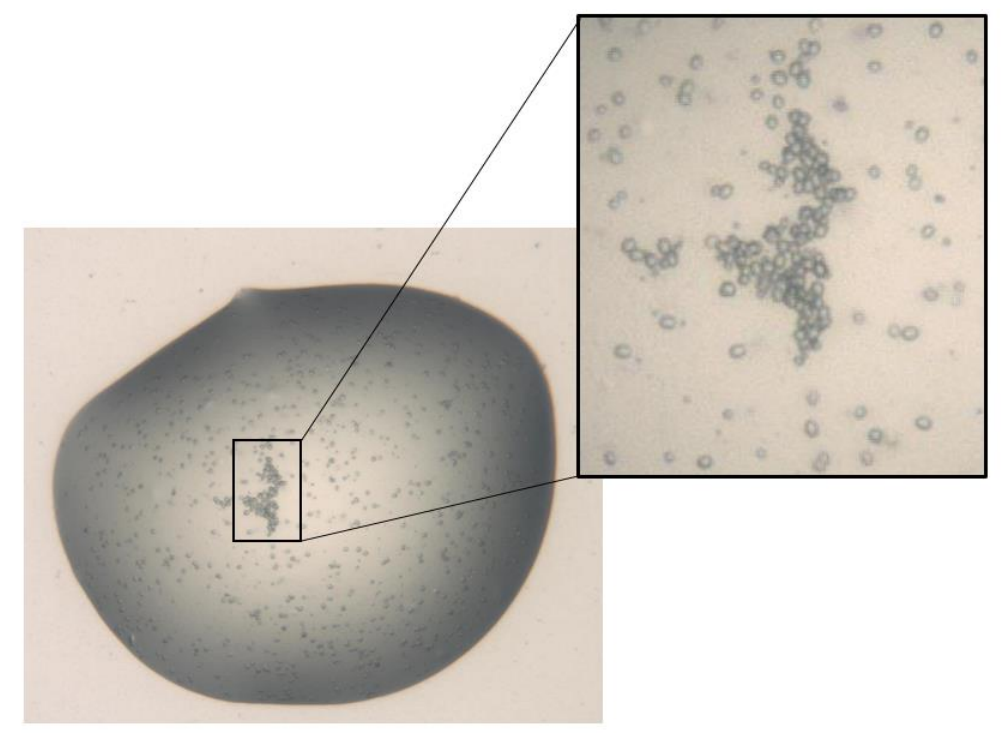

Figure S4. Self-crystallization of Tb-Xo4 (at $0.1 \mathrm{M}$ concentration) during automated HTX experiments in the following condition: crystallization kit The Classics suite; condition F10; composition: ammonium sulfate $0.2 \mathrm{M}$, sodium cacodylate $0.1 \mathrm{M}$, pH 6.5, PEG $800030 \%$.

\section{5) Single-Crystal X-ray diffraction}

Good quality single-crystals of 1, 3 and 4 were mounted on an Oxford Diffraction Gemini and, for 2, on an Oxford Diffraction Xcalibur Saphir 3 diffractometer, both equipped with graphite monochromatized Mo Ka radiation $(\lambda=0.71073 \AA)$ fine-focus sealed tubes. Intensity data were collected at $293(\mathbf{1}, 3$ and 4) and $100 \mathrm{~K}(2)$. Crystal data of three samples were collected using a Gemini (Oxford Diffraction, 2006). ${ }^{\text {ix }}$ Data refinement and reduction were performed using the CrysAlis software. Analytical absorption corrections were applied to the intensity values in case of complexes 1 and 3.xi The structures were solved by direct methods using the programs SIR97xii and refined using the programs CRYSTALS xiii (1 and 3) and SHELXL97xiv (2). All non-hydrogen atoms were refined anisotropically. C-bound hydrogen atoms in $\mathbf{1}$ and $\mathbf{2}$ were placed geometrically and refined using a riding model approximation. $\mathrm{H}$ atoms for water (coordinated or not) were located in the difference map and the positions were restrained to minimize $\mathrm{H} \cdots \mathrm{H}$ clashes. In case of complex 1, we present the best model we have been able to obtain concerning potential $\mathrm{H} \cdots \mathrm{H}$ clashed.

CCDC-1405178 (1), -620315 (2), -1405177 (3) and -2041987 (4) references contain the supplementary crystallographic data. These data can be obtained free of charge from The Cambridge Crystallographic Data Centre via www.ccdc.cam.ac.uk/data_request/cif 
Table S4. Crystallographic details and structure refinement results for complexes 1, 2 and 3.

\begin{tabular}{|c|c|c|c|c|}
\hline & 1 & 2 & 3 & 4 \\
\hline Formula & $\mathrm{C}_{42} \mathrm{H}_{66} \mathrm{Eu}_{2} \mathrm{Mg}_{3} \mathrm{~N}_{6} \mathrm{O}_{49}$ & $\mathrm{C}_{84} \mathrm{H}_{140} \mathrm{Ca}_{6} \mathrm{Eu}_{4} \mathrm{~N}_{12} \mathrm{O}_{100}$ & $\mathrm{C}_{7} \mathrm{H}_{7} \mathrm{Cu}_{1} \mathrm{~N}_{1} \mathrm{O}_{6}$ & $\mathrm{C}_{20} \mathrm{H}_{26.50} \mathrm{Cl}_{2} \mathrm{~N}_{5} \mathrm{O}_{7} \mathrm{~Tb}_{1}$ \\
\hline Formula weight $\left(\mathrm{g} \cdot \mathrm{mol}^{-1}\right)$ & 1815.8 & 3766.4 & 264.7 & 678.8 \\
\hline Crystal system & monoclinic & monoclinic & monoclinic & tetragonal \\
\hline Space group & $\mathrm{Pc}$ & $\mathrm{C} 2 / \mathrm{c}$ & $\mathrm{P} 2{ }_{1} / \mathrm{c}$ & $\mathrm{P} 42 / \mathrm{n}$ \\
\hline $\mathbf{a}(\AA)$ & $10.6852(4)$ & $32.3441(9)$ & $7.2189(5)$ & $18.015(1)$ \\
\hline b $(\AA)$ & $16.0221(6)$ & $18.7074(5)$ & $19.068(2)$ & $18.015(1)$ \\
\hline c $(\AA)$ & $21.3470(7)$ & $24.1301(6)$ & $6.4321(5)$ & $18.438(1)$ \\
\hline $\boldsymbol{\beta}$ (deg.) & $103.969(4)$ & $108.689(2)$ & $107.042(8)$ & 90 \\
\hline $\mathbf{V}\left(\AA^{3}\right)$ & $3546.5(2)$ & $13830.6(6)$ & $846.5(1)$ & $5984.3(6)$ \\
\hline $\mathbf{Z}$ & 2 & 4 & 4 & 8 \\
\hline$\rho_{\text {cal }}\left(\mathrm{g} . \mathrm{cm}^{-3}\right)$ & 1.706 & 1.809 & 2.075 & 1.507 \\
\hline Crystal shape & needle & block & needle & block \\
\hline Crystal color & colorless & colorless & blue & colorless \\
\hline Crystal size $\left(\mathrm{mm}^{3}\right)$ & $0.05 \times 0.07 \times 0.37$ & $0.30 \times 0.30 \times 0.32$ & $0.24 \times 0.26 \times 0.75$ & $0.51 \times 0.64 \times 0.72$ \\
\hline $\boldsymbol{\mu}\left(\mathrm{mm}^{-1}\right)$ & 1.897 & 2.137 & 2.588 & 2.584 \\
\hline $\mathbf{T}(\mathrm{K})$ & 293 & 100 & 293 & 150 \\
\hline No. reflections / $\mathbf{R}_{\text {int }}$ & $27103 / 0.040$ & 101882 / 0.045 & 3966 / 0.024 & 6785 / 0.034 \\
\hline No. reflections used & 10608 & 15059 & 1777 & 4836 \\
\hline No. parameters refined & 920 & 932 & 137 & 348 \\
\hline$R(F) / R_{w}(F)[I / \sigma(I)>2]$ & $0.0516 / 0.0664$ & $0.0371 / 0.1036$ * & 0.0307 / 0.0336 & $0.0681 / 0.0865$ \\
\hline $\mathrm{s}$ & 1.33 & 1.11 & 1.10 & 1.36 \\
\hline$\Delta \rho_{\max } / \Delta \rho_{\min }\left(\mathrm{e}^{-} . \AA^{-3}\right)$ & $+1.91 /-1.84$ & $+3.51 /-1.66$ & $+0.48 /-0.68$ & $+3.28 /-2.17$ \\
\hline Absorption correction & & none & & analytical \\
\hline
\end{tabular}

${ }^{*} \mathrm{R}\left(\mathrm{F}^{2}\right) / \mathrm{R}_{\mathrm{w}}\left(\mathrm{F}^{2}\right)[\mathrm{I} / \sigma(\mathrm{I})>2]$ 
Table S5. Important bond lengths (Á) for complex 1.

\begin{tabular}{|rrrrrr|}
\hline Eu1-O1 & $2.483(7)$ & Eu1-O11 & $2.475(6)$ & Eu1-N9 & $2.533(8)$ \\
Eu1-O21 & $2.452(7)$ & Eu1-N25 & $2.531(7)$ & Eu1-O32 & $2.429(7)$ \\
Eu1-O41 & $2.431(7)$ & Eu1-O51 & $2.476(6)$ & Eu1-N49 & $2.536(8)$ \\
Eu38-O61 & $2.441(7)$ & Eu38-N65 & $2.543(8)$ & Eu38-O71 & $2.486(7)$ \\
Eu38-O81 & $2.507(6)$ & Eu38-N89 & $2.522(8)$ & Eu38-O91 & $2.418(7)$ \\
Eu38-O141 & $2.432(7)$ & Eu38-N149 & $2.507(8)$ & Eu38-O152 & $2.423(7)$ \\
Mg82-O101 & $2.037(8)$ & $\mathrm{Mg} 82-\mathrm{O} 102$ & $2.084(8)$ & $\mathrm{Mg} 82-\mathrm{O} 103$ & $2.086(9)$ \\
$\mathrm{Mg} 82-\mathrm{O} 104$ & $2.073(7)$ & $\mathrm{Mg} 82-\mathrm{O} 105$ & $2.087(8)$ & $\mathrm{Mg} 82-\mathrm{O} 106$ & $2.046(8)$ \\
$\mathrm{Mg} 75-\mathrm{O} 111$ & $2.086(9)$ & $\mathrm{Mg} 75-\mathrm{O} 112$ & $2.110(9)$ & $\mathrm{Mg} 75-\mathrm{O} 113$ & $2.071(8)$ \\
$\mathrm{Mg} 75-\mathrm{O} 114$ & $2.066(9)$ & $\mathrm{Mg} 75-\mathrm{O} 115$ & $2.090(9)$ & $\mathrm{Mg} 75-\mathrm{O} 116$ & $2.048(9)$ \\
$\mathrm{Mg} 89-\mathrm{O} 121$ & $2.050(9)$ & $\mathrm{Mg} 89-\mathrm{O} 122$ & $2.060(8)$ & $\mathrm{Mg} 89-\mathrm{O} 123$ & $2.101(8)$ \\
$\mathrm{Mg} 89-\mathrm{O} 124$ & $2.069(9)$ & $\mathrm{Mg} 89-\mathrm{O} 125$ & $2.043(9)$ & $\mathrm{Mg} 89-\mathrm{O} 126$ & $2.07(1)$ \\
\hline
\end{tabular}

Table S6. $\mathrm{SHAPE}^{\mathrm{xv}}$ analysis for $\mathrm{Eu}(\mathrm{III})\left\{\mathrm{O}_{8} \mathrm{~N}_{3}\right\}$ environment within crystal structure of $\mathbf{1}$.

\begin{tabular}{|c|c|c|c|c|c|c|}
\hline \multirow{4}{*}{$\overline{|c|}$} & OPY-9 & HBPY-9 & JTC-9 & JCCU-9 & CCU-9 & JCSAPR-9 \\
\hline & 22.87 & 18.49 & 14.17 & 10.03 & 8.80 & 1.98 \\
\hline & CSAPR-9 & JTCTPR-9 & TCTPR-9 & JTDIC-9 & HH-9 & MFF-9 \\
\hline & 1.01 & 2.34 & 1.37 & 10.88 & 11.68 & 1.64 \\
\hline \multirow{4}{*}{ 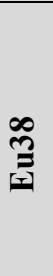 } & OPY-9 & HBPY-9 & JTC-9 & JCCU-9 & CCU-9 & JCSAPR-9 \\
\hline & 23.21 & 17.69 & 13.65 & 9.64 & 8.44 & 2.06 \\
\hline & CSAPR-9 & JTCTPR-9 & TCTPR-9 & JTDIC-9 & HH-9 & MFF-9 \\
\hline & 1.09 & 2.26 & 1.40 & 10.74 & 11.37 & 1.65 \\
\hline
\end{tabular}




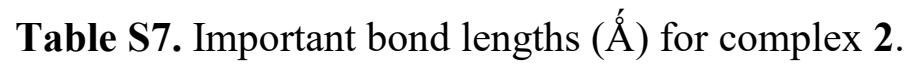

\begin{tabular}{|llllll|}
\hline Eu1-O21 & $2.429(3)$ & Eu1-O14 & $2.442(3)$ & Eu1-O24 & $2.444(3)$ \\
Eu1-O11 & $2.446(3)$ & Eu1-O4 & $2.453(3)$ & Eu1-O1 & $2.459(3)$ \\
Eu1-N21 & $2.524(3)$ & Eu1-N11 & $2.541(3)$ & Eu1-N1 & $2.562(3)$ \\
Eu2-O51 & $2.427(3)$ & Eu2-O31 & $2.428(3)$ & Eu2-O43 & $2.428(3)$ \\
Eu2-O54 & $2.440(3)$ & Eu2-O41 & $2.444(3)$ & Eu2-O34 & $2.473(3)$ \\
Eu2-N41 & $2.519(3)$ & Eu2-N51 & $2.522(3)$ & Eu2-N31 & $2.560(3)$ \\
Ca1-O13 & $2.402(3)$ & Ca1-O52 & $2.410(3)$ & Ca1-O64 & $2.484(3)$ \\
Ca1-O63 & $2.535(3)$ & Ca2-O2 & $2.287(3)$ & Ca2-O70 & $2.309(3)$ \\
Ca2-O67 & $2.353(3)$ & Ca2-O68 & $2.361(3)$ & Ca2-O94 & $2.363(3)$ \\
Ca3-O22 & $2.399(3)$ & Ca3-O44 & $2.454(3)$ & Ca3-O62 & $2.459(3)$ \\
Ca3-O61 & $2.501(3)$ & Ca3-O53 & $2.275(3)$ & Ca4-O66 & $2.306(3)$ \\
Ca4-O65 & $2.401(3)$ & Ca5-O23 & $2.271(3)$ & Ca5-O69 & $2.309(3)$ \\
Ca5-O96 & $2.400(3)$ & & & & \\
\hline
\end{tabular}

Table S8. SHAPE analysis for Eu(III) $\left\{\mathrm{O}_{8} \mathrm{~N}_{3}\right\}$ environment within crystal structure of 2 .

\begin{tabular}{|c|c|c|c|c|c|c|}
\hline \multirow{4}{*}{$\bar{\Xi}$} & OPY-9 & HBPY-9 & JTC-9 & JCCU-9 & CCU-9 & JCSAPR-9 \\
\hline & 22.99 & 18.22 & 14.06 & 8.95 & 7.80 & 2.49 \\
\hline & CSAPR-9 & JTCTPR-9 & TCTPR-9 & JTDIC-9 & HH-9 & MFF-9 \\
\hline & 1.64 & 2.14 & 1.17 & 10.32 & 11.64 & 2.13 \\
\hline \multirow{4}{*}{$\cong$} & OPY-9 & HBPY-9 & JTC-9 & JCCU-9 & CCU-9 & JCSAPR-9 \\
\hline & 23.56 & 18.48 & 13.64 & 9.59 & 8.42 & 2.39 \\
\hline & CSAPR-9 & JTCTPR-9 & TCTPR-9 & JTDIC-9 & HH-9 & MFF-9 \\
\hline & 1.52 & 1.95 & 1.10 & 10.54 & 12.17 & 2.07 \\
\hline
\end{tabular}




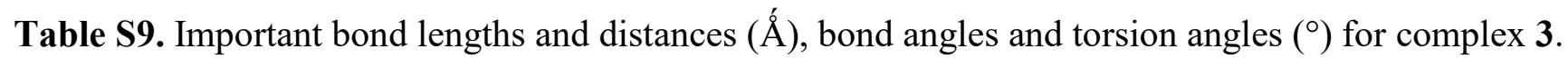

\begin{tabular}{|rlrlrl|}
\hline $\mathrm{Cu} 1-\mathrm{O} 3$ & $2.43242)$ & $\mathrm{Cu} 1-\mathrm{O} 2$ & $1.943(2)$ & $\mathrm{Cu} 1-\mathrm{O} 3$ & $2.062(2)$ \\
$\mathrm{Cu} 1-\mathrm{N} 7$ & $1.899(2)$ & $\mathrm{Cu} 1-\mathrm{O} 13$ & $2.044(2)$ & $\mathrm{Cu} 1-\mathrm{O} 15$ & $2.405(2)$ \\
$\mathrm{Cu}{ }^{\cdots} \mathrm{Cu}{ }^{\cdots} \mathrm{Cu}$ & 3.869 & $\mathrm{Cu}{ }^{\cdots} \mathrm{Cu}{ }^{\cdots} \mathrm{Cu}$ & 8.222 & & \\
intra-chain & & Shortest inter-chain & & & \\
\hline O3-Cu1-O2 & $84.20(7)$ & O3-Cu1-O3 & $99.21(7)$ & & \\
O3-Cu1-N7 & $91.98(7)$ & O2-Cu1-N7 & $174.76(7)$ & O3-Cu1-N7 & $80.38(9)$ \\
O3-Cu1-O13 & $83.59(8)$ & O2-Cu1-O13 & $95.61(8)$ & O3-Cu1-O13 & $160.62(6)$ \\
N7-Cu1-O13 & $80.37(9)$ & O3-Cu1-O15 & $169.56(6)$ & O2-Cu1-O15 & $88.28(7)$ \\
O3-Cu1-O15 & $89.60(7)$ & N7-Cu1-O15 & $95.04(7)$ & O13-Cu1-O15 & $89.96(9)$ \\
\hline
\end{tabular}

Table S10. Important bond lengths (Á) for complex 4.

\begin{tabular}{|rrrrrr|}
\hline Tb1 - O23 & $2.265(6)$ & Tb1 - O2 & $2.416(7)$ & Tb1 - N6 & $2.521(7)$ \\
Tb1 - N9 & $2.685(8)$ & Tb1 - N12 & $2.648(7)$ & Tb1 - N15 & $2.491(9)$ \\
Tb1 - N20 & $2.484(7)$ & Tb1 - O24 & $2.389(6)$ & Tb1 - O31 & $2.449(7)$ \\
\hline
\end{tabular}

Table S11. SHAPE analysis for Tb(III) $\left\{\mathrm{O}_{4} \mathrm{~N}_{5}\right\}$ environment within crystal structure of 4 .

\begin{tabular}{|c|c|c|c|c|c|c|}
\hline \multirow{4}{*}{$\bar{E}$} & OPY-9 & HBPY-9 & JTC-9 & JCCU-9 & CCU-9 & JCSAPR-9 \\
\hline & 23.08622 & 17.38200 & 15.20241 & 8.03853 & 6.98477 & 2.75143 \\
\hline & CSAPR-9 & JTCTPR-9 & TCTPR-9 & JTDIC-9 & HH-9 & \\
\hline & 1.80723 & 2.90731 & 2.18716 & 11.87311 & 7.71756 & \\
\hline
\end{tabular}




\section{6) Photophysical measurements in solution.}

Emission spectra were measured using Horiba-Jobin-Yvon Fluorolog-3 fluorimeter on concentrated solutions $\left(10^{-3} \mathrm{M}\right)$. The steady-state luminescence was excited by unpolarized light from a $450 \mathrm{~W}$ xenon continuous wave (CW) lamp and detected at an angle of $22.5^{\circ}$ for measurements of dilute solutions (10 mm quartz cuvette) either by using a Hamamatsu R928 or Peltier cooled R2658 photomultiplier tube. Spectra were corrected for both excitation source light-intensity variation and emission spectral responses.

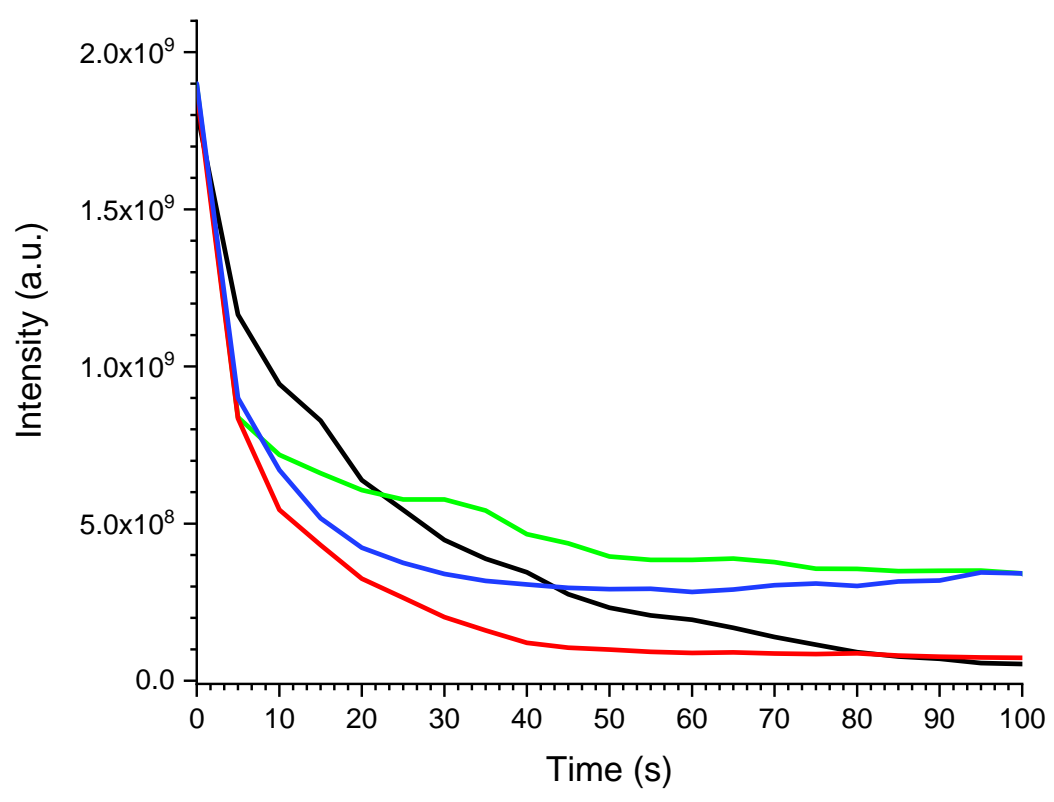

Figure S5. Evolution of the Eu(III) emission intensity after addition of 1 equivalent of divalent transition metal to $[\mathrm{Na}]_{3}\left[\mathrm{Eu}(\mathrm{DPA})_{3}\right]$ at time $=0 \mathrm{~s}\left(\mathrm{C}\left([\mathrm{Na}]_{3}\left[\mathrm{Eu}(\mathrm{DPA})_{3}\right)=\mathrm{C}\left(\mathrm{MCl}_{2}\right)=1,0610^{-3} \mathrm{M},\left[\mathrm{MCl}_{2}\right]=\mathrm{CdCl}_{2}\right.\right.$ (green), $\mathrm{ZnCl}_{2}$ (blue), $\mathrm{CoCl}_{2}$ (red) or $\mathrm{NiCl}_{2}$ (black), $\lambda_{\text {exc }}=283 \mathrm{~nm}, \lambda_{\mathrm{em}}=614 \mathrm{~nm}$, front face, $\mathrm{H}_{2} \mathrm{O}$, room temperature). 


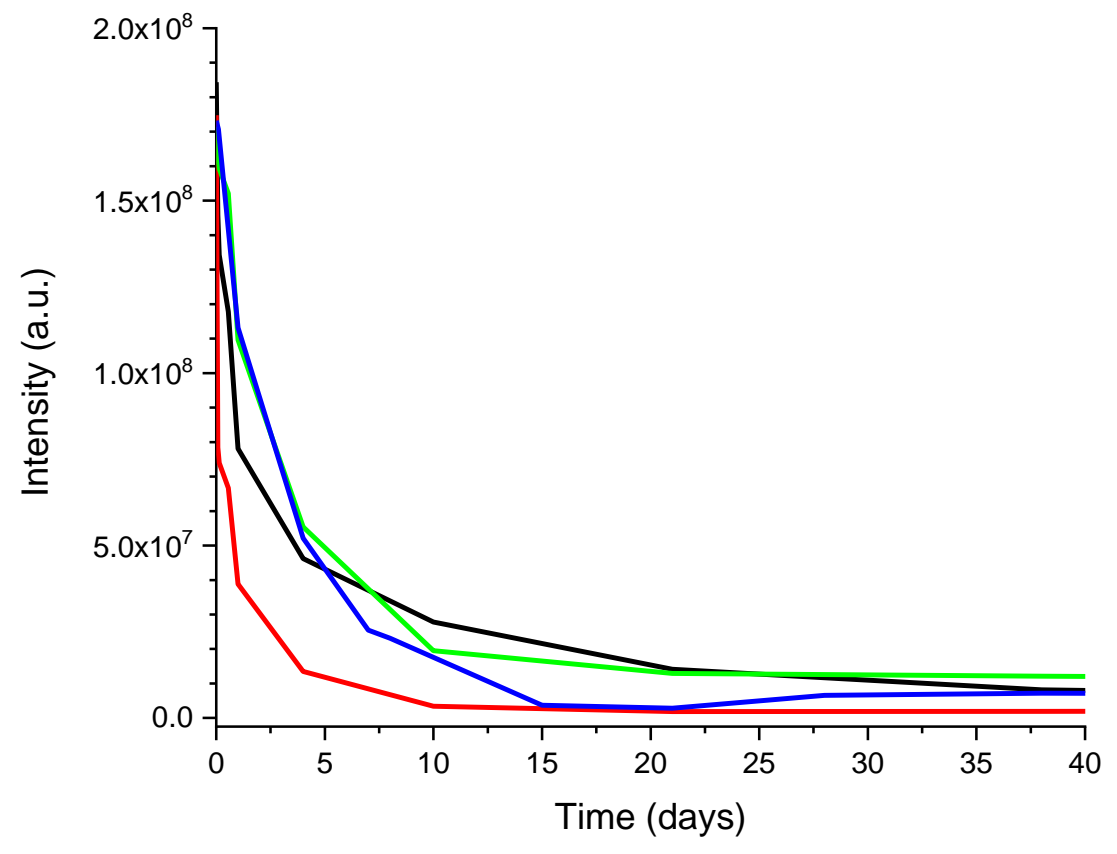

Figure S6. Evolution of the $\mathrm{Tb}(\mathrm{III})$ emission intensity of Tb-Xo4 after addition of 1 equivalent of divalent transition metal $\left(\mathrm{C}[\mathrm{Tb}-\mathrm{Xo} 4]=\mathrm{C}\left[\mathrm{MCl}_{2}\right] \sim 10^{-3} \mathrm{M},\left[\mathrm{MCl}_{2}\right]=\mathrm{CdCl}_{2}\right.$ (green), $\mathrm{ZnCl}_{2}$ (blue), $\mathrm{CoCl}_{2}$ (red) or $\mathrm{NiCl}_{2}$ (black), $\lambda_{\mathrm{exc}}=273 \mathrm{~nm}, \lambda_{\mathrm{em}}=488 \mathrm{~nm}$, front face, $\mathrm{H}_{2} \mathrm{O}$, room temperature)

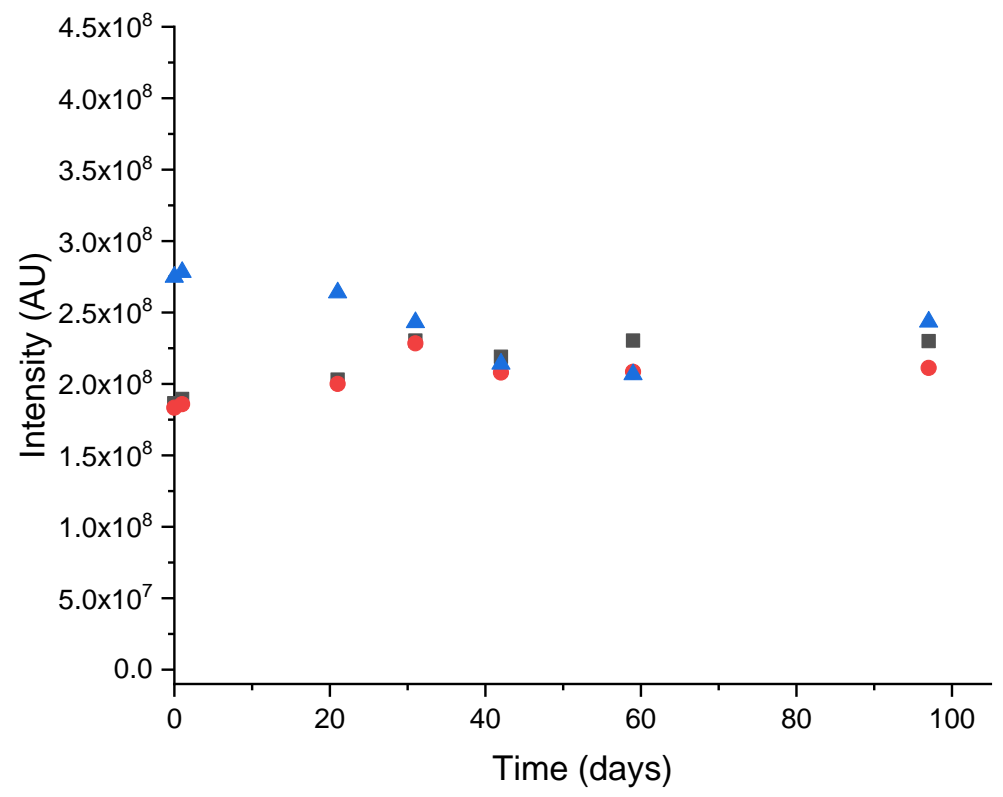

Figure S7. Evolution of the Tb-Xo4 emission intensity after addition of 1-10 eq of alkaline-earth salts $\left(\mathrm{C}[\mathrm{Tb}-\mathrm{Xo} 4] \sim 1 \mathrm{mM}, \mathrm{C}\left[\mathrm{CaCl}_{2}\right]=1.1\right.$ to $11 \mathrm{mM}(\mathbf{\bullet}), \mathrm{C}\left[\mathrm{MgCl}_{2}\right]=1.1$ to $11 \mathrm{mM}(\bullet), \mathrm{C}\left[\mathrm{BaAc}_{2}\right]=1.0$ to $10 \mathrm{mM}(\Delta), \lambda_{\text {exc }}=273 \mathrm{~nm}, \lambda_{\mathrm{em}}=488 \mathrm{~nm}$, front face, $\mathrm{H}_{2} \mathrm{O}$, room temperature). 


\section{References and notes.}

\footnotetext{
${ }^{\mathrm{i}}$ Tancrez, N. ; Feuvrie, C. ; Ledoux, I. ; Zyss, J. ; Toupet, L. ; Le Bozec, H. ; Maury O. J. Am. Chem. Soc., 2005, 127, 13474-13475.

ii Engilberge, S., Riobé, F., Di Pietro, S. ; Lassalle, L. ; Coquelle, N. ; Arnaud, C. ; Madern, D. ; Breyton, C. ; Maury, O. ; Girard E. Chem. Science. 2017, 8, 5909-5917.
}

iii Jiang, T.; Roux, A. ; Engilberge, S. ; Alsalman, Z. ; Di Pietro, S. ; Franzetti, B. ; Riobé, F. ; Maury, O. ; Girard E. Cryst. Growth \& Design. 2020, 20, 5322-5329

iv a) Pos, K.M.; Diederichs, K. Acta Crystallogr., D Biol. Crystallogr. 2002, 58,1865-1867 ; b) Stroebel D. ; Sendra, V. ; Cannella, D. ; Helbig, K. ; Covès J. Biochimica et Biophysica Acta 2007, 1768, 15671573.

v a) Wagner, T., Koch, J., Ermler, U., Shima, S. Science, 2017, 357, 699-703.; b) Engilberge, S.; Wagner, T.; Santoni, G.; Breyton, C.; Shima, S.; Franzetti, B.; Riobe, F.; Maury, O.; Girard, E. J. Appl. Crystallogr. 2019, 52, 722.

${ }^{v i}$ Engilberge, S.; Riobé, F.; Wagner, T.; Di Pietro, S.; Breyton, C.; Franzetti, B.; Shima, S.; Girard, E.; Dumont, E.; Maury O. Chem. Eur. J. 2018, 24, 9739-9746.

vii Søndergaard, C. R.; Olsson, M. H. M.; Rostkowski, M.; Jensen J. H. J. Chem. Theory Comput. 2011, 7, 22842295

viii Gaussian 16, Revision B.01, Frisch M. J.; Trucks, G. W.; Schlegel, H. B.; Scuseria, G. E.; Robb, M. A.; Cheeseman, J. R.; Scalmani, G.; Barone, V.; Petersson, G. A.; Nakatsuji, H.; Li, X.; Caricato, M.; Marenich, A. V.; Bloino, J.; Janesko, B. G.; Gomperts, R.; Mennucci, B.; Hratchian, H. P.; Ortiz, J. V.; Izmaylov, A. F.; Sonnenberg, J. L.; Williams-Young, D.; Ding, F.; Lipparini, F.; Egidi, F.; Goings, J.; Peng, B.; Petrone, A.; Henderson, T.; Ranasinghe, D.; Zakrzewski, V. G.; Gao, J.; Rega, N.; Zheng, G.; Liang, W.; Hada, M.; Ehara, M.; Toyota, K.; Fukuda, R.; Hasegawa, J.; Ishida, M.; Nakajima, T.; Honda, Y.; Kitao, O.; Nakai, H.; Vreven, T.; Throssell, K.; Montgomery, J. A., Jr.; Peralta, J. E.; Ogliaro, F.; Bearpark, M. J.; Heyd, J. J.; Brothers, E. N.; Kudin, K. N.; Staroverov, V. N.; Keith, T. A.; Kobayashi, R.; Normand, J.; Raghavachari, K.; Rendell, A. P.; Burant, J. C.; Iyengar, S. S.; Tomasi, J.; Cossi, M.; Millam, J. M.; Klene, M.; Adamo, C.; Cammi, R.; Ochterski, J. W.; Martin, R. L.; Morokuma, K.; Farkas, O.; Foresman, J. B.; Fox, D. J. Gaussian, Inc., Wallingford CT, 2016.

ix CrysAlisPro, v. 1.171.33.46 (rel. 27-08-2009 CrysAlis171.NET), Oxford Diffraction Ltd., 2009.

x De Meulenaer, J. ; Tompa, H. Acta Crystallogr. 1965, 19, 1014-1018.

${ }^{x i}$ Blessing, R. H. Acta Crystallogr., Sect. A: Found. Crystallogr. 1995, 51, 33-38.

xii Altomare, A. ; Burla, M. C. ; Camalli, M. ; Cascarano, G. L. ; Giacovazzo, C. ; Guagliardi, A. ; Moliterni, A. G. G. ; Polidori, G. ; Spagna, R. J. Appl. Crystallogr. 1999, 32, 115-119.

xiii Watkin, D. J.; Prout, C. K.; Carruthers, J. R.; Betteridge P. W. in CRISTAL Issue 11, Chemical Crystallography Laboratory, Oxford, 1999. 
xiv Sheldrick, G.M. (1997). SHELX97. Program for the Refinement of Crystal Structures, Univ. of Göttingen, Germany.

xv Llunell, M.; Casanova, D.; Cirera, J.; Bofill, J. M.; Alemany, P.; Alvarez, S. SHAPE (Version 2.1) 2013 